\title{
Ir@Pt bimetallic overlayer catalysts for aqueous phase glycerol hydrodeoxygenation
}

Chen Zhang, Qinghua Lai, Joseph H. Holles*

\author{
Department of Chemical Engineering \\ University of Wyoming \\ 1000 E. University Ave. \\ Laramie, WY - 82071
}

* To whom correspondence should be addressed

jholles@uwyo.edu

(307) 766-6772

Fax: (307) 766-2221

(C) 2016. This manuscript version is made available under the Elsevier user license http://www.elsevier.com/open-access/userlicense/1.0/ 
Abstract:

Silica-alumina supported bimetallic overlayer catalysts of platinum on Ir (Ir@Pt) were synthesized using the directed deposition technique to investigate the modification of the Pt catalytic properties. Weakened hydrogen adsorption strength was obtained for Ir@Pt overlayer catalysts compared to pure platinum using hydrogen chemisorption and an ethylene hydrogenation descriptor reaction, consistent with literature computational studies. This reduced adsorption strength is expected to increase the Pt overlayer reactivity compared to pure Pt by releasing Pt active sites from strongly adsorbed $\mathrm{H}_{2}$ or $\mathrm{CO}$. The effect of multiple Pt overlayer depositions is also studied, and it is postulated that overlayer catalysts with double and triple platinum overlayer deposition would form Pt multilayer structure. Multiple overlayers displayed a smaller degree of modification in $\mathrm{H}_{2}$ adsorption strength from pure Pt, compared to Ir@Pt single deposition sample. In aqueous phase glycerol hydrodeoxygenation, Ir@Pt single deposition sample showed higher turnover frequencies of glycerol conversion and $\mathrm{C}_{3}$ hydrocarbon production than pure Pt and the bimetallic alloy sample. The activity enhancement of Ir@Pt compared to pure Pt is ascribed to the weakened hydrogen adsorption of Ir@Pt, as fewer Pt active sites were blocked by strong $\mathrm{H}_{2}$ or $\mathrm{CO}$ adsorption. The improved selectivity toward $\mathrm{C}_{3}$ hydrocarbons of Ir@Pt compared to pure Pt suggested a feasible approach of using overlayer catalysts to manipulate the selectivity of Pt overlayer without sacrificing the Pt overlayer reactivity.

\section{Keywords:}

Overlayer catalysts;

Glycerol;

Hydrodeoxygenation;

Adsorption;

Iridium; 


\section{Introduction:}

Aqueous phase hydrodeoxygenation (APH) of biomass feedstocks provides a promising approach to produce transportation fuels, platform chemicals and carbon based materials [1]. Two important processes are involved in APH of biomass: $\mathrm{C}-\mathrm{O}$ bond cleavage to produce hydrocarbons and CC bond cleavage to produce syngas $\left(\mathrm{CO}\right.$ and $\left.\mathrm{H}_{2}\right)$ [2]. $\mathrm{C}-\mathrm{O}$ bond scission is crucial for the production of bioderived fuels by removing oxygen from biomass feedstocks in order to increase the energy density and stability without reducing the carbon chain length [3]. In contrast, C-C bond scission of biomass feedstocks provides a feasible way to produce hydrogen from renewable biomass [4]. Bifunctional catalysts combining solid acid supports and active metals have been demonstrated to be effective for $\mathrm{APH}$, with solid acid supports to catalyze dehydration/deoxygenation reactions and active metals to catalyze dehydrogenation, hydrogenation and decarbonylation reactions. [5-8]. Among different metals studied, platinum is widely used as a metal catalyst with high reactivity in aqueous phase hydrodeoxygenation of biomass. However, the scarcity of platinum hinders the extensive application of platinum catalysts in biomass conversion. Additionally, research on aqueous phase reforming and fuel cells suggested that the strong binding of hydrogen and carbon monoxide products, and oxygen intermediates on the platinum surface would negatively affect the catalyst reactivity as a result of the blockage of active sites [8-10]. Therefore, an efficient and effective way of utilizing platinum becomes imperative for enhanced catalytic reactivity in biomass reactions.

Bimetallic overlayer catalysts consisting of a monolayer of one metal atop a different bulk metal provide a promising option to tackle the challenges of Pt utilization due to their unique adsorption properties [11-13]. Computational studies have predicted that a Pt overlayer atop certain metals, such as $\mathrm{Ni}$ or $\mathrm{Co}$, will show a decreased d-band center energy, which could be correlated with decreased adsorption strength of $\mathrm{H}_{2}$ and $\mathrm{CO}$ [14-16]. Such a reduction in $\mathrm{H}_{2}$ and $\mathrm{CO}$ adsorption strength is expected to improve the catalytic reactivity of the Pt overlayer in reactions where hydrogen is involved, as weaker 
hydrogen binding strength would indicate a lower degree of Pt site blockage. Also, the amount of Pt used in Pt overlayer catalysts could be reduced significantly as all deposited Pt is on the surface. In previous work, Ni@Pt and Co@Pt (core@shell) overlayer catalysts supported on silica-alumina were synthesized for aqueous phase hydrodeoxygenation of glycerol [17]. Hydrogen chemisorption and ethylene hydrogenation reaction descriptors revealed that reduced hydrogen binding strength of overlayer catalysts compared to pure $\mathrm{Pt}$, as predicted by various computational and experimental studies [11, 12], has been achieved for both Ni@Pt and Co@Pt [17]. Both overlayer catalysts displayed enhanced turnover frequencies (TOF) toward hydrocarbon production in APH of glycerol compared to pure metal and non-structured bimetallic counterparts. However, platinum overlayer coverages in these overlayer catalysts were relatively low (26\% for Ni@Pt and 6\% for Co@Pt), likely due to the difference in the interatomic distance between parent metals (Ni or Co of $2.52 \AA$ ) and the overlaying metal (Pt of 2.76 Å) [18]. A further enhancement of overlayer catalyst productivity is expected if the platinum overlayer coverage could be increased. Moreover, the hydrocarbon product distribution of platinum overlayer catalysts (Ni@Pt and Co@Pt) resembles the parent metal (Ni or $\mathrm{Co}$ ). Because both $\mathrm{Ni}$ and Co are active in C-C bond breaking $[17,19]$, Ni@Pt and Co@Pt produced a large amount of C-C bond cleavage products in the product stream, while in bio-derived fuel production, C-C bond breaking is less desired to avoid carbon chain scission.

While most bimetallic surface studies used single crystal substrate as the host metal, herein we present aqueous phase glycerol hydrodeoxygenation over supported Ir@Pt (core@shell) overlayer catalysts. Computational predictions proposed that the platinum overlayer on top of iridium would display a reduced d-band center energy [14] and weakened adsorption strength of hydrogen [15]. Such a reduction in adsorption strength of the Pt overlayer compared to pure Pt suggests higher reactivity in APH of Ir@Pt than pure Pt due to fewer blockages of Pt sites by strongly adsorbed $\mathrm{H}_{2}, \mathrm{CO}$, and oxygen intermediates $[3,8]$. The close covalent radius of iridium $(1.41 \AA)$ relative to platinum $(1.36 \AA)$ [20] is 
expected to result in a higher platinum coverage of Ir@Pt than Ni@Pt and Co@Pt, due to a lower degree of atomic size mismatch (compared to $\mathrm{Pt}$ on $\mathrm{Ni}$ or $\mathrm{Co}$ ). Also, iridium was observed to be selective in catalyzing $\mathrm{C}-\mathrm{O}$ bond cleavage relative to $\mathrm{C}-\mathrm{C}$ bond cleavage in producing 1,3-propanediol from glycerol hydrogenolysis $[21,22]$. Therefore, a platinum overlayer atop iridium is predicted to display higher reactivity and selectivity for the production of renewable fuels from APH compared to pure Pt, as well as result in a relatively high platinum overlayer coverage.

In this work, glycerol is used as a model compound for APH, due to its high availability from biodiesel production, and structural similarity and simplicity compared to sugar alcohol biomass [23, 24]. Silica-alumina, which has been shown to possess a relatively high amount of both Brønsted and Lewis acid sites [25], is used as the solid acid support for all catalysts to provide necessary acid functionality to catalyze the dehydration/deoxygenation reactions. Ir@Pt overlayer catalysts are synthesized using the directed deposition technique, which has been reported to successfully synthesize Re@Pd, Ni@Pt, and Co@Pt overlayer catalysts [17, 26, 27]. Multiple platinum depositions (double and triple depositions) are conducted to study the behaviors of increased platinum overlayer coverage. $\mathrm{H}_{2}$ chemisorption and an ethylene hydrogenation descriptor reaction are performed to study the hydrogen adsorption properties. Aqueous phase glycerol hydrodeoxygenation is tested to demonstrate the promotional effect of overlayer deposition on reactivity and selectivity toward C-O scission. The APH of 1-propanol and 2propanol using overlayer catalysts is also tested as probe reactions to provide insight for the C-O bond scission of primary and secondary alcohols.

\section{Experimental:}

\subsection{Catalyst Synthesis}

$2 \mathrm{wt} . \% \mathrm{Ir} / \mathrm{SiO}_{2}-\mathrm{Al}_{2} \mathrm{O}_{3}$ parent catalyst was synthesized using incipient wetness impregnation of silica-alumina Siral70 (Sasol, 99.97\%) with the solution of dihydrogen hexachloroiridate(IV) hydrate (Alfa 
Aesar 99\%). 5 wt.\% and 0.5 wt.\% $\mathrm{Pt} / \mathrm{SiO}_{2}-\mathrm{Al}_{2} \mathrm{O}_{3}$ control catalysts were prepared from a slurry of silicaalumina Siral 70 (Sasol, 99.97\%) and platinum(II) acetylacetonate (Alfa Aesar) in toluene. 5 wt.\% Pt sample was used for hydrogen chemisorption studies, and 0.5 wt.\% Pt was used for ethylene hydrogenation and glycerol APH so that the number of metal active sites per gram of catalyst is similar to Ir-based catalysts. Non-structured bimetallic Ir-Pt/SiO${ }_{2}-\mathrm{Al}_{2} \mathrm{O}_{3}$ catalyst was also made with the similar loading as the overlayer samples using incipient wetness impregnation. Following impregnation all catalysts were dried in an oven overnight. The iridium parent and the Ir-Pt bimetallic catalyst were calcined in near stagnant air at $500^{\circ} \mathrm{C}$ for $3 \mathrm{~h}$ [21], while pure Pt catalyst was calcined at $400^{\circ} \mathrm{C}$ for $3 \mathrm{~h}$ [17]. The catalysts were then reduced under $60 \mathrm{sccm} \mathrm{H}_{2}$ flow at calcined temperatures for $3 \mathrm{~h}$.

The overlayer catalysts used in this paper were prepared using the directed deposition technique $[17,28]$. This technique is adapted from the refilling method developed by Womes et al. [29] The parent $\mathrm{Ir} / \mathrm{SiO}_{2}-\mathrm{Al}_{2} \mathrm{O}_{3}$ catalyst (8-10 grams) was reduced in $60 \mathrm{sccm} \mathrm{H}_{2}$ flow at $500^{\circ} \mathrm{C}$ for $3 \mathrm{~h}$ using a $3^{\circ} \mathrm{C} / \mathrm{min}$ ramp rate. The catalyst was then cooled to room temperature and water-saturated helium gas was passed over the catalyst for $24 \mathrm{~h}$. The iridium parent catalyst was then briefly reduced at $50^{\circ} \mathrm{C}$ in 60 sccm $\mathrm{H}_{2}$ flow for $1 \mathrm{~h}$. This reduction temperature was found to be where the parent catalyst had maximum irreversible $\mathrm{H}_{2}$ adsorption. The reduced catalyst was then added to a $40 \mathrm{~mL}$ toluene solution of $0.1 \mathrm{M}$ acetylacetone, used as a surface inhibitor to ensure low platinum adsorption on the support at room temperature [26]. The surface deactivation was allowed to proceed for 15 min before a toluene solution of $0.5 \mathrm{M} \mathrm{Pt}(\mathrm{II})$ acetylacetonate was added. The amount of $\mathrm{Pt}(\mathrm{II})$ acetylacetonate added is equivalent to $100 \%$ coverage of the Ir surface. The reaction was allowed to proceed at $60^{\circ} \mathrm{C}$ for $2 \mathrm{~h}$, during which $\mathrm{Pt}(\mathrm{II})$ acetylacetonate underwent a hydrogenation reaction with adsorbed hydrogen on the metal particles, resulting in the deposition of the overlayer metal. The catalyst was then vacuum filtered to remove liquid and allowed to dry in the fume hood. The sample was then placed in an $110^{\circ} \mathrm{C}$ drying oven overnight to fully dry the catalyst. The catalyst was loaded into a quartz tube to be calcined in near 
stagnant air at $400^{\circ} \mathrm{C}$ for $3 \mathrm{~h}$ using a $3^{\circ} \mathrm{C} / \mathrm{min}$ ramp rate up and down. After calcination the catalyst was reduced in $10 \mathrm{sccm} \mathrm{H}_{2}$ flow at $500^{\circ} \mathrm{C}$ for $3 \mathrm{~h}$ using a $3^{\circ} \mathrm{C} / \mathrm{min}$ ramp rate for the total reduction of Ir particles [30]. Multiple overlayer depositions were done by repeating the above procedure to produce single, double, and triple deposition Ir@Pt samples, denoted as Ir@Pt SD, Ir@Pt DD, and Ir@Pt TD, respectively.

\subsection{Sample Characterization Studies}

Elemental analysis was conducted in the Geochemistry Analytical Laboratory, University of Wyoming. The elemental analysis of the catalysts was carried out by inductively coupled plasma atomic emission spectroscopy (ICP-AES) using a Perkin Elmer inductively coupled plasma optical emission spectrometer. Transmission electron microscopy (TEM) images were recorded with JEOL JEM-2100F high-resolution transmission electron microscopes at Colorado State University. Hydrogen chemisorption studies were conducted using a Micromeritics ASAP 2020. Hydrogen isotherms were gathered at temperatures between $100^{\circ} \mathrm{C}$ and $350^{\circ} \mathrm{C}$ at pressures ranging from 1 mTorr to 900 Torr. Heats of $\mathrm{H}_{2}$ adsorption were calculated using Clausius-Clapeyron equation for the ideal gas [28].

Reactivity studies were conducted using an ethylene hydrogenation descriptor reaction. The details of the experiment are described elsewhere [26]. All turnover frequencies for monometallic catalysts were calculated using the number of surface metal sites determined with metal loading and dispersion results. Dispersion values used in turnover frequency calculations were determined from $\mathrm{H}_{2}$ chemisorption at $35^{\circ} \mathrm{C}$ as reported in Table 1.

\subsection{Activity Testing:}

The aqueous phase glycerol hydrodeoxygenation reaction was performed in an up-flow fixed bed tubular reactor [17]. An aqueous solution of $10 \mathrm{wt} . \%$ glycerol was introduced using a high- 
performance liquid chromatography (HPLC) pump. The reaction was conducted at 25.6 bar. Gaseous products were analyzed by a Trace GC Ultra equipped with a flame ionization detector (FID) and a thermal conductivity detector (TCD). The FID was equipped with a Restek Q-Bond capillary column, and the TCD is equipped with a Haysep DB packed column. Liquid effluent was analyzed by an Agilent Technologies 1260 Infinity HPLC equipped with a Bio-Rad Aminex HPX-87H ion exclusion column (300 $\mathrm{mm} \times 7.8 \mathrm{~mm}$ ). A $0.005 \mathrm{M} \mathrm{H}_{2} \mathrm{SO}_{4}$ aqueous solution was used as a carrier at a flow rate of $0.9 \mathrm{~mL} / \mathrm{min}$. Column and detector temperatures were set to $35^{\circ} \mathrm{C}$.

\section{Results and discussion}

All samples were supported on silica-alumina (Siral 70), and for brevity, catalyst nomenclature will omit the support, unless otherwise specified.

\subsection{Elemental analysis of metal loadings}

Platinum loadings for each catalyst are reported in Table 1. As-synthesized values for iridium loadings were used due to its insolubility in acidic solutions. Metal dispersions and average metal particle sizes measured by total $\mathrm{H}_{2}$ chemisorption at $35^{\circ} \mathrm{C}$ are also shown in Table 1 (no distinction was

made as to the metal type). The surface platinum coverages of overlayer samples were calculated using the dispersion value and assuming $100 \%$ platinum dispersion from elemental analysis. $43 \%$ of iridium atoms exposed are covered by platinum atoms for Ir@Pt SD. For Ir@Pt DD and Ir@Pt TD, the platinum overlayer coverages are about $109 \%$ and $172 \%$ of the original Ir surface, respectively. Since the calculated platinum coverage is higher than the monolayer coverage $(100 \%), 100 \%$ coverage will be used for Ir@Pt DD and Ir@Pt TD in the following sections for reactivity normalization purposes. The overlayer coverage of Ir@Pt DD (109\%) increased more than two times that of Ir@Pt SD (43\%), while the weight loading increased only two times (from $0.12 \mathrm{wt. \%}$ to $0.24 \mathrm{wt} . \%$ ). This is because the dispersion of Ir@Pt SD (10.8\%) is lower than the Ir parent sample (14.6\%), so that theoretically less metallic surface is 
exposed for Ir@Pt SD than the Ir parent. Although the amount of Pt deposited during the third deposition is equivalent to about $70 \%$ of total metal surface area in the double deposition sample, the decrease in dispersion from Ir@Pt DD (11.2\%) to Ir@Pt TD (9.0\%) validates that the direct deposition technique utilized in this study will not deposit overlaying metal onto the support surface, because the dispersion of the triple deposition sample would increase dramatically if even a small fraction of these Pt atoms was deposited on the support surface.

Previous studies of Ni@Pt and Co@Pt supported on silica-alumina and y-alumina showed limited Pt overlayer coverages for overlayer catalysts $[17,27]$. Silica-alumina supported Ni@Pt and Co@Pt showed platinum overlayer coverages of $26 \%$ and $6 \%$, respectively. For $\gamma$-alumina-supported samples, Pt coverages are less than 15\% for up to triple deposition Ni@Pt and Co@Pt samples. According to X-ray adsorption spectroscopy (XAS) results, it is speculated that the difference in the interatomic distance between parent metals (Ni or Co of $2.52 \AA$ ) and the overlaying metal (Pt of $2.76 \AA$ ) is the inhibiting factor for high overlayer coverages [18]. This assumption is supported by this study with Ir@Pt overlayer catalysts, as higher Pt overlayer coverages than previous Ni@Pt and Co@Pt overlayer catalysts are achieved, likely due to the fact that the covalent radius of iridium (1.41 $\AA$ ) is closer to platinum (1.36 $\AA$ ) than Ni (1.24 $\AA$ ) or Co (1.26 ̊̊) [20]. The higher Pt coverages obtained here with Ir@Pt overlayer catalysts agree with the expectation, demonstrating the important role of size matching between the host metal (in this study, Ir) and the overlayer metal (Pt) in obtaining high overlayer coverage catalysts.

\subsection{X-ray diffraction}

Figure 1 shows the XRD patterns of all catalysts synthesized. All catalysts containing iridium displayed two distinct peaks at $2 \theta=40.5^{\circ}$ and $47.1^{\circ}$, which correspond to metallic $\operatorname{Ir}(111)$ and $\operatorname{Ir}(200)$, respectively. Iridium oxide phases were not detected, indicating that all iridium catalysts were fully reduced. A small shoulder representing Pt (111) phase at $2 \theta=39.1^{\circ}$ was observed in Ir-Pt bimetallic 
catalyst, while this peak was not observed for Ir@Pt SD. This shoulder from Ir-Pt suggested bulk Pt agglomeration of the bimetallic catalyst. It is not clear if there is a similar Pt peak in the Ir@Pt DD or TD catalyst. However, the Pt weight loading for Ir@Pt DD is greater than Ir-Pt bimetallic and Ir@Pt TD is twice the weight loading of Ir-Pt. Thus, even if there is some Pt agglomeration in these two samples, the Pt atoms are still highly dispersed and any agglomeration is less than the Ir-Pt bimetallic sample.

The Ir crystallite sizes for all Ir-based catalysts and the Pt crystallite size for pure Pt catalysts calculated using the Scherrer's equation are shown in Table 1. Since the majority of the metal particle is Ir, determining particle size based on Ir alone provides a representative value of the particle size. Ir crystallite sizes calculated from XRD are slightly different from the particle sizes calculated from $\mathrm{H}_{2}$ chemisorption, however, results from both measurements are consistent, indicating that the particle size (or the iridium crystallite size) of Ir parent particles in the overlayer catalysts increased slightly after each overlayer deposition. This is not unexpected as the calcination during each procedure could lead to agglomeration of Ir parent particles.

\subsection{Transmission electron microscopy}

Transmission electron microscopy (TEM) images of Ir@Pt SD are shown in Figure 2(a) and 2(b). High-angle annular dark field scanning transmission electron microscopy (HAADF-STEM) imaging and energy-dispersive $\mathrm{x}$-ray spectroscopy (EDX) mapping were used to investigate the dispersion of Pt in the overlayer catalyst. As can be seen in Figure 2(c) and 2(d), Pt atoms are well dispersed on the Ir parent metal particles and show no evidence of agglomeration. Also, it is probable that Pt atoms are only located on the Ir parent particles, as no substantial Pt signal was detected outside the Ir particle. An EDX line scan was also conducted as shown in Figure 2(e) and 2(f). The Pt signal was distributed evenly along the marked line, while an evident peak was noticed for the Ir signal as the scan crossed the particle. This 
indicates that Pt element is likely to be more concentrated on the surface (or the edge) rather than in the bulk of the Ir parent particles, which could be correlated with the desired overlayer structure.

\subsection{Hydrogen chemisorption}

Table 2 shows the maximum heats of hydrogen adsorption for each catalyst calculated by the Clausius-Clapeyron equation (no distinction was made as to the metal type) [26]. Pure platinum exhibited the highest heat of adsorption $(59 \mathrm{~kJ} / \mathrm{mol}$ ) among all catalysts tested in this study, similar to the heat of $\mathrm{H}_{2}$ adsorption Sen and Vannice obtained for $\mathrm{Pt} / \mathrm{SiO}_{2}(67 \mathrm{~kJ} / \mathrm{mol})$ with the same platinum particle size $(1.6 \mathrm{~nm})$ [31]. The pure Ir sample (with a metal particle size of $7.6 \mathrm{~nm}$ ) in this study showed a heat of $\mathrm{H}_{2}$ adsorption of $36 \mathrm{~kJ} / \mathrm{mol}$. This value is also consistent with the previous study by Guil et al., reporting the heat of $\mathrm{H}_{2}$ adsorption for $\mathrm{Ir} / \gamma-\mathrm{Al}_{2} \mathrm{O}_{3}$ with a particle size of $10.8 \mathrm{~nm}$ to be within the range of 35 to $40 \mathrm{~kJ} / \mathrm{mol}$ under monolayer hydrogen coverage [32]. The Ir-Pt bimetallic catalyst exhibited a value intermediate to pure platinum and pure iridium as expected, because this bimetallic catalyst is a simple combination of both metals.

The Ir@Pt single deposition catalyst displayed a heat of $\mathrm{H}_{2}$ adsorption of $28 \mathrm{~kJ} / \mathrm{mol}$. This heat of adsorption was lower than that of the pure platinum and pure iridium. Such a reduction of overlayer catalyst heat of adsorption compared to the pure overlayer metal is consistent with previous $\mathrm{H}_{2}$ chemisorption studies on Re@Pd, Ni@Pt, and Co@Pt overlayer catalysts using the same synthesis technique $[26,27]$ and computational predictions which proposed that such an overlayer structure could reduce the $d$-band center energy and hence weaken the adsorption strength of hydrogen [15]. Ir@Pt double and triple deposition catalyst showed heats of hydrogen adsorption higher than the Ir@Pt

single deposition and closer to that of pure platinum, indicating a smaller degree of adsorption modification to the platinum overlayer in the Ir@Pt DD and TD samples compared to the Ir@Pt SD. Therefore, considering the assumption that Pt aqueous phase hydrodeoxygenation reactivity is hindered 
by strong adsorption of $\mathrm{H}_{2}, \mathrm{CO}$, and oxygenated intermediates $[8,10]$, Ir@Pt SD is likely to exhibit higher reactivity in aqueous phase glycerol hydrodeoxygenation than pure Pt, Ir@Pt DD, and Ir@Pt TD due to the weakest hydrogen adsorption of Ir@Pt SD.

A correlation between measured heats of hydrogen adsorption of overlayer catalysts reported in this work and previous study [17] and the d-band center energy of corresponding ideal bimetallic surface catalysts calculated by Ruban et al. [14] has been made as shown in Figure 3. All three overlayer catalysts presented in the figure were synthesized with the same procedure and the same silica-alumina (Sasol Siral 70) support. The values of hydrogen heat of adsorption for Ni@Pt SD and Co@Pt SD overlayer catalyst are adopted from previous study [17]. For Ni@Pt SD and Ir@Pt SD, d-band center energies for the surface overlayer structure were chosen due to the relatively high platinum overlayer coverage of both samples (26\% for Ni@Pt SD and 42\% for Ir@Pt SD). In contrast, the d-band center energy for surface impurities was adopted for Co@Pt SD because of its relatively low platinum overlayer coverage (6\%) (a detailed argument is presented elsewhere [17]). It could be seen from the figure that the calculated hydrogen heats of adsorption of the three overlayer catalysts showed a positive relationship with predicted d-band center energies. This correlation agrees well with other experimental or computational studies, where hydrogen binding strength for overlayer catalysts was observed to be positively related to the d-band center energy $[12,33,34]$. The correlation in this study implied that calculated hydrogen heat of adsorption would be an indicator of the d-band center energy and vice versa for bimetallic overlayer catalysts.

\subsection{Ethylene Hydrogenation Results}

Ethylene hydrogenation is used as a descriptor for hydrogen adsorption strength, because ethylene hydrogenation reactivity is a strong function of hydrogen adsorption strength and hydrogen surface coverage [26]. Results of the ethylene hydrogenation studies can be seen in the Arrhenius-type 
plot shown in Figure 4. Calculated apparent activation energies and reaction orders with respect to hydrogen and ethylene are presented in Table 3.

The turnover frequency (TOF) of this reaction for the Pt-only catalyst was orders of magnitude higher than the Ir-only catalyst, indicating that the ethylene hydrogenation reactivity of the overlayer catalysts could be attributed exclusively to any platinum present on the surface and discounting the contribution of any exposed iridium sites. In this respect, for the single deposition catalyst, the TOF was normalized using the measured platinum loading with an assumed platinum dispersion of $100 \%$. For double and triple deposition catalysts, because the amount of Pt obtained from elemental analysis is higher than the monolayer coverage of iridium parent particles, dispersion values obtained from hydrogen chemisorption were used for normalizing the TOF. Monometallic catalyst turnover frequencies were calculated based on active sites of iridium or platinum. The non-structured bimetallic Ir-Pt alloy turnover frequency was calculated based on surface metal atoms (from dispersion; no distinction was made as to the metal type). The Weisz-Prater criterion is calculated for this reaction and the value indicated that the reaction rate is not limited by pore diffusion (details are presented in the supplementary information).

All catalysts displayed a positive hydrogen reaction order as shown in Table 3, indicating a positive dependence of the hydrogenation reaction rate on the surface hydrogen coverage. The Arrhenius-type plot of Figure 4 graphically shows relative reaction rates and apparent activation energies for ethylene hydrogenation reaction over all catalysts. Although nearly $40 \%$ of the iridium surface is covered by the platinum overlayer, the turnover frequency of Ir@Pt SD is still an order of magnitude lower than pure platinum. This observation is in accordance with hydrogen chemisorption results that the overlayer structure will weaken the surface hydrogen adsorption strength and thus decrease surface hydrogen coverage, resulting in a lower reaction rate for ethylene hydrogenation. The 
Ir-Pt bimetallic catalyst displayed a TOF value intermediate to pure platinum and pure iridium as expected, considering it as a simple mixture of two metals. The distinct difference between the three overlayer catalysts and the Ir-Pt bimetallic catalyst demonstrates the difference in structures and catalytic properties.

Ir@Pt DD and Ir@Pt TD displayed nearly identical ethylene hydrogenation TOF (if normalized by dispersion), and reaction orders with respect to ethylene and hydrogen, despite the fact that platinum loading increased about 60\% from Ir@Pt DD to Ir@Pt TD. Additionally, $\mathrm{H}_{2}$ heats of adsorption from $\mathrm{H}_{2}$ chemisorption are similar for Ir@Pt DD and Ir@Pt TD. These similarities between Ir@Pt DD and Ir@Pt TD are consistent with previous computational studies of $\mathrm{Pd} / \mathrm{Au}(111)$ [35] and $\mathrm{Pt} / \mathrm{Ru}(0001)$ overlayer systems [36]. Roudgar et al. reported $\mathrm{H}_{2}$ and $\mathrm{CO}$ adsorption strength on $\mathrm{Pd} / \mathrm{Au}(111)$ would remain almost unchanged rather than relax back to pure $\mathrm{Pd}$ from $3 \mathrm{Pd}$ overlayers to infinitely many $\mathrm{Pd}$ overlayers [35]. Lischka et al. also noticed that Pt on top of Ru(0001) with 3 to 5 layers of Pt exhibited roughly the same oxygen binding energy rather than moving toward pure Pt [36]. It is observed in both studies that the influence from underlying substrate is the strongest for the first two overlayers, and starting from the third layer, adsorption energies converged to the adsorption energy of infinitely many overlayers, but still different from the pure overlaying metal $[35,36]$. This agrees well with observations in this study that the triple deposition sample showed similar behaviors to the double deposition sample, while the single deposition sample was significantly different from the double (or triple) deposition sample in all aspects.

Differences in $\mathrm{H}_{2}$ chemisorption and ethylene hydrogenation between pure Pt and Ir@Pt DD or TD clearly demonstrate that the surface Pt on Ir@Pt DD and Ir@Pt TD is not behaving as bulk Pt. This is in agreement with previous x-ray adsorption spectroscopy study on Ni@Pt overlayer catalysts supported on $\gamma$-alumina using the same synthesis technique, where the Pt-Pt interatomic distance shifted toward 
pure Pt (2.76 ̊) from Ni@Pt SD (2.67 ̊̊) to Ni@Pt DD (2.73 $)$ ), but remained almost unchanged from Ni@Pt DD (2.73 Å) to Ni@Pt TD (2.72 Å) [18]. This size disparity between overlayer Pt and bulk Pt even after multiple depositions likely results from the strain effect between the underlying substrate and the overlaying metal. Although no data for Pt overlayer on Ir were found, it is reported that the strain effect resulting from lattice mismatch between host metal and overlayer metal is effective for up to eight overlayers for Pt/Ru(0001) [16]. Therefore, Pt overlayers on Ir@Pt DD and Ir@Pt TD are expected to behave as a structure of Pt multilayers, but still essentially different from pure Pt, due to the lattice strain from the underlying iridium. This assumption is corroborated by the absence of clear Pt peaks in XRD results, showing no evidence of Pt agglomeration in either Ir@Pt DD or Ir@Pt TD although the platinum loadings are higher than Ir-Pt bimetallic sample.

Ir@Pt SD showed the lowest $\mathrm{H}_{2}$ heat of adsorption, ethylene hydrogenation TOF, and thus the highest degree of adsorption modification away from pure Pt comparing to Ir@Pt DD and Ir@Pt TD. This is expected as the Pt overlayer on Ir@Pt SD is most strongly affected by the electronic interaction between substrate (Ir) and overlayer Pt. Accordingly, Ir@Pt SD is likely to display the highest reactivity in aqueous phase glycerol hydrodeoxygenation compared to double and triple deposition samples, because of its lowest $\mathrm{H}_{2}$ adsorption strength and thereby the least Pt site blockage by $\mathrm{H}_{2}, \mathrm{CO}$, and oxygenated intermediates that are strongly adsorbed.

\subsection{Glycerol Hydrodeoxygenation using Overlayer Catalysts:}

The catalysts were evaluated for their performance in the aqueous phase glycerol hydrodeoxygenation reaction at $300^{\circ} \mathrm{C}$ at a weight hour space velocity (WHSV = mass flow/catalyst mass) of $4 \mathrm{~h}^{-1}$. Turnover frequencies of monometallic catalysts and Ir-Pt bimetallic catalyst were normalized by the $\mathrm{H}_{2}$ chemisorption sites. For overlayer catalysts, in order to rule out the interference of surface iridium, the turnover frequencies were calculated by subtracting the contribution of iridium 
surface sites from the production rates and then normalizing the rest of production rates based on the platinum surface atoms. The detailed calculation is presented in the supplementary information. Pore diffusion is found to not inhibit the reaction according to Weisz-Prater criterion and details could also be found in the supplementary information.

Blank tests (no catalysts) using the same reaction condition showed no glycerol conversion. This indicates the absence of aqueous phase glycerol decomposition under the reaction condition. The hydrodeoxygenation of glycerol over the silica-alumina support (with no metal) under experimental conditions was also tested. Glycerol conversion at $300^{\circ} \mathrm{C}$ over silica-alumina was $13.1 \%$, significantly lower than those of metal-catalyzed reactions. 1,2-Propanediol and 1,3-propanediol were detected as the main products ( $>60 \%$ selectivity), along with a small fraction of $\mathrm{C}-\mathrm{C}$ bond breaking products such as ethylene glycol. No gaseous products were detected, suggesting that silica-alumina support as a solid acid is able to catalyze $\mathrm{C}-\mathrm{C}$ bond and $\mathrm{C}-\mathrm{O}$ bond breaking, but much less active compared to metal components such as iridium or platinum. This is consistent with previous studies on the bifunctional mechanism of $\mathrm{APH}$, indicating that a combination of metal and acid function is required for the effective hydrodeoxygenation $[5,6]$.

TOF of hydrocarbon production rates at $300^{\circ} \mathrm{C}$ over iridium-based catalysts are shown in Figure 5. Hydrocarbons detected include methane, ethane, ethylene, propane, and propylene. All catalysts favored $C_{3}$ hydrocarbons (no $C-C$ bond scission) over $C_{1}$ and $C_{2}$ hydrocarbons (C-C bond scission). Although Ir@Pt SD and pure platinum produced a nearly equivalent amount of carbon atoms in the form of $C_{1}$ and $C_{2}$ hydrocarbons, overlaying Pt active sites of Ir@Pt SD exhibited a higher TOF for $C_{3}$ hydrocarbon, which is desirable for selective C-O bond scission. Pure Ir and Ir-Pt showed lower TOF in hydrocarbon production than pure Pt and Ir@Pt SD, leading to the conclusion that the activity improvement of Ir@Pt SD mainly results from the Pt overlayer. Ir-Pt is less active in hydrocarbon 
production, clearly demonstrating the structural difference between the non-structured bimetallic catalyst and the overlayer catalyst.

Glycerol conversion and product selectivity values for all catalysts at $300^{\circ} \mathrm{C}$ are shown in Table 4 . Liquid products could be divided into two categories: decarbonylation products and deoxygenation products. Decarbonylation products detected in the liquid phase include ethanol, ethylene glycol, acetic acid, methanol, and formic acid, all of which were formed via C-C cleavage from glycerol. Deoxygenation products detected in the liquid phase include 1,2-propanediols, 1,3-propanediols, 1-propanol, 2propanol, and lactic acid. These deoxygenation products were formed via C-O bond scission with no C-C bond scission. All catalysts showed selectivity of $C_{3}$ alcohols (1,2-propanediols, 1,3-propanediols, 1propanol, and 2-propanol combined) higher than 50\%. This is consistent with the hydrocarbon production rate results, suggesting the preference of $\mathrm{C}-\mathrm{O}$ bond scission (deoxygenation) over $\mathrm{C}-\mathrm{C}$ bond scission (decarbonylation). Ir@Pt SD, DD, and TD showed $\mathrm{C}_{3}$ alcohols selectivity of $60.1 \%, 65.7 \%$, and $77.0 \%$, respectively, higher than that of pure Pt (52.7\%) and Ir-Pt (54.5\%). This demonstrates the advantage of overlayer catalysts in selectively breaking C-O bonds compared to pure Pt or the Ir-Pt bimetallic alloy.

The Ir-Pt bimetallic catalyst showed relatively low TOF of glycerol conversion and hydrocarbon production compared to other catalysts. Based on the synthesis technique and the weight loading, Ir-Pt is expected to consist mostly of Ir particles with a limited amount of surface Pt sites and thus behave similarly to pure Ir. The reason for lower reactivity of Ir-Pt than pure Ir is not immediately apparent. A possible explanation is the increased dispersion of $\operatorname{Ir}-\mathrm{Pt}$ (21.9\%) than pure $\operatorname{Ir}(14.6 \%)$. For comparison, Shi et al. studied the hydrogenolytic cleavage of cyclohexane over different dispersions of iridium supported on $y$-alumina. It was demonstrated that the turnover frequency of cyclohexane conversion 
decreased by a factor of 5 with increasing Ir dispersion in the range of 0-20\% dispersion [37], similar to what was observed in this study where the activity decreased as dispersion increased.

Ir@Pt DD and Ir@Pt TD showed much lower hydrocarbon production rates per active site than Ir@Pt SD as shown in Figure 5. A possible cause for such low reactivity is the agglomeration of surface Pt atoms in Ir@Pt DD and Ir@Pt TD. Previous XAS studies have revealed that Pt overlayer is likely to agglomerate when additional deposition procedures were applied [18]. Although XRD results in this study suggested the absence of Pt crystallites in all overlayer samples, it is speculated that the Pt overlayer structure in Ir@Pt DD and Ir@Pt TD was compromised. In this respect, the actual number of surface Pt sites was decreased from Ir@Pt SD so that the reactivity was reduced for Ir@Pt DD and Ir@Pt TD. Therefore, Ir@Pt SD is a better representation of desired overlayer structure compared to Ir@Pt DD and Ir@Pt TD due to its weakest $\mathrm{H}_{2}$ adsorption strength and highest hydrocarbon production rate per active site.

The effect of weight hour space velocity (WHSV) ranging from $4 \mathrm{~h}^{-1}$ to $32 \mathrm{~h}^{-1}$ was investigated at $300^{\circ} \mathrm{C}$ under the same reaction conditions by changing glycerol feed flow rate. Hydrogen feed flow rate was also modified to keep the hydrogen/glycerol ratio constant. The Ir@Pt single deposition catalyst was chosen as the representative overlayer catalyst due to it having the highest TOF for hydrocarbon production among the overlayer catalysts. Pure iridium and pure platinum were chosen as comparisons. The TOF for glycerol conversion at different WHSV is shown in Figure 6. At WHSV $=4 \mathrm{~h}^{-1}$ (the same condition as in Figure 5), pure iridium displayed lower activity in glycerol conversion than pure platinum and Ir@Pt SD, while Ir@Pt SD was slightly less active than pure platinum. For all other flow rates, Ir@Pt SD showed increased TOF with increasing WHSV and surpassed pure platinum, while pure Ir still displayed the lowest TOF for glycerol conversion. Previous aqueous phase reforming studies proposed that strong $\mathrm{H}_{2}$ and $\mathrm{CO}$ adsorption is likely to block Pt active sites and thus decrease the catalytic 
reactivity of Pt catalysts $[3,8]$. This conclusion is validated in this study by the reduced $\mathrm{H}_{2}$ adsorption strength and increased TOF in glycerol conversion of Ir@Pt SD compared to pure Pt, as the reduced hydrogen adsorption strength of the platinum overlayer on Ir@Pt SD suggested that more Pt active sites become available for the reaction.

The TOF for $\mathrm{C}_{3}$ hydrocarbon production at different WHSV are shown in Figure 7. The TOF for pure Ir, pure Pt and Ir@Pt SD at WHSV=4 $\mathrm{h}^{-1}$ in this figure are different from the value reported in Figure 5. This likely results from the different time on stream in these two experiments, but TOF decreased in the same order (Ir@Pt SD > pure Pt > pure Ir). Pure iridium exhibited a relatively low TOF toward hydrocarbon production, indicating its low reactivity in hydrodeoxygenation. Ir@Pt SD produced more $\mathrm{C}_{3}$ hydrocarbons per platinum active site than pure platinum at all WHSV with the advantage of the Ir@Pt SD over pure Pt increasing as the WHSV increased. This increased reactivity, along with the result of the TOF for glycerol conversion (Figure 6), demonstrated that Ir@Pt surpassed pure Pt in both hydrocarbon production and glycerol conversion on a per site basis at most flow rates tested (the only exception is WHSV $=4 \mathrm{~h}^{-1}$ ).

The Higher TOF for $\mathrm{C}_{3}$ hydrocarbon production of Ir@Pt SD indicates a relative higher selectivity than pure Pt in C-O cleavage vs. C-C cleavage. This improvement in selectivity could be ascribed mostly to the presence of the Pt overlayer of Ir@Pt SD, while the synergistic effect between Ir sites and Pt sites is regarded as the less significant factor due to the relatively low reactivity of the Ir-Pt bimetallic sample compared to Ir@Pt SD as shown previously. Literature studies proposed that the metal/acid site balance is important for the selectivity of aqueous phase hydrodeoxygenation [6-8]. This factor, however, is considered to be less significant in this study when determining the reactivity and selectivity advantages of Ir@Pt SD compared to pure Pt, as both catalysts were supported on the same support and had a similar number of exposed metal and acid sites. It is postulated that the Pt overlayer in Ir@Pt SD 
possessed reduced adsorption strength for surface adsorbents compared to pure platinum so that the $C_{3}$ hydrocarbon production rates increased. One crucial adsorbent that might affect the $\mathrm{C}-\mathrm{C}$ bond cleavage is glyceraldehyde, which was not detected in the liquid phase in this study likely due to the fast reaction rate of glyceraldehyde decarbonylation or disproportionation $[38,39]$. Glyceraldehyde is considered to be the key intermediate for C-C bond cleavage in glycerol hydrogenolysis on noble metal surfaces [40, 41] and is the kinetically relevant step for glycerol decarbonylation (C-C scission) [39, 42]. By comparing the glycerol hydrogenolysis selectivity of Rh, Ru, Pt and Pd, Wang et al. proposed that the Ru displayed the strongest adsorption of glyceraldehyde and thus the dehydrogenation of glycerol to glyceraldehyde is more kinetically favored, leading to an increased selectivity to C-C bond cleavage [39]. These observations could also account for the higher selectivity toward $C_{3}$ hydrocarbons of Ir@Pt SD than pure Pt. The weaker adsorption of glyceraldehyde on overlaying Pt active sites will suppress the glyceraldehyde formation from glycerol compared to pure Pt. The C-C bond cleavage is therefore inhibited in glycerol conversion of Ir@Pt SD compared to pure Pt, because the glycerol dehydrogenation reaction forming glyceraldehyde is more rate-limiting compared to the subsequent $\mathrm{C}-\mathrm{C}$ bond cleavage from glyceraldehyde to form $C_{2}$ and $C_{1}$ compounds [39]. Moreover, Courtois et al. calculated the activation energy of $\mathrm{CHCO}$ dissociation, which is a crucial C-C scission step in ethanol fuel cells [43]. It was determined that with Pt overlayer atop Ir, the activation energy for CHCO dissociation is increased so that $\mathrm{C}-\mathrm{C}$ bond breaking is less favorable. This is consistent with the current research that $\mathrm{C}-\mathrm{C}$ bond cleavage is inhibited for Ir@Pt SD relative to pure Pt.

Another advantage of Ir@Pt SD compared to pure platinum is the reduced production rates of carbon oxides $\left(\mathrm{CO}\right.$ and $\mathrm{CO}_{2}$ ). The ratios of carbon oxides selectivity to $\mathrm{C}_{3}$ hydrocarbon selectivity as a function of WHSV are shown in Figure 8. Carbon oxides can be correlated with the reactivity of C-C bond cleavage, as evidence has shown carbon oxides are formed via decarbonylation from aldehydes [38, 44]. In order to achieve high $\mathrm{C}-\mathrm{O}$ bond scission selectivity, less carbon oxides are expected in the product 
stream. At WHSV=8,16,24, and $32 \mathrm{~h}^{-1}$, the ratio of $\mathrm{CO}_{\mathrm{x}}$ selectivity vs. $\mathrm{C}_{3}$ hydrocarbons is above 20 and as high as 50 for pure Pt, which means every carbon atom in a $C_{3}$ hydrocarbon is co-produced with more than 20 carbon atoms in the form of carbon oxides at these reaction conditions. This high selectivity to carbon oxides is consistent with previous aqueous phase reforming studies, as platinum is an excellent catalyst for converting biomass molecules into syngas $\left(\mathrm{H}_{2}\right.$ and $\left.\mathrm{CO}\right)[3,10]$. However, $\mathrm{CO}_{x}$ is less desirable for effective biomass conversion to bio-derived fuels, as a large quantity of carbon atoms from biomass feedstock is not converted to target products. Pure Ir displayed a much lower ratio of carbon oxides to $\mathrm{C}_{3}$ hydrocarbon (less than 5 at all WHSV) compared to pure Pt. This demonstrates the excellent selectivity of pure Ir in breaking $\mathrm{C}-\mathrm{O}$ bonds with relatively low reactivity for $\mathrm{C}-\mathrm{C}$ bond cleavage, in agreement with literature studies that iridium showed high selectivity for glycerol hydrogenolysis to produce propanediols [45-47]. For Ir@Pt SD, the ratio of carbon oxides selectivity to $C_{3}$ hydrocarbon selectivity is much lower than pure platinum. Especially at high WHSV of 24 and $32 \mathrm{~h}^{-1}$, this ratio is only one fifth of that of pure platinum. Also, by relating the TOF for hydrocarbon production as shown in Figure 7 with the carbon oxides selectivity ratio as shown in Figure 8 , it can be seen that at relatively high WHSV, Ir@Pt SD showed higher potential in hydrocarbon production than pure platinum as well as less carbon oxides as byproducts. Such an advantage implies promising applications in bio-derived fuel production from biomass for the Ir@Pt overlayer catalyst.

As shown in Figure 8, Ir@Pt SD displayed a selectivity ratio intermediate to pure Pt and pure Ir. One explanation for this intermediate selectivity is the contribution from the exposed iridium surface in Ir@Pt SD. The turnover frequency in glycerol conversion of pure Ir is about $15 \%$ to $35 \%$ of pure Pt as shown in Figure 6. Accordingly, it is suggested that the exposed Ir surface in Ir@Pt SD contributed to the overall product distribution and shifting the overall selectivity of Ir@Pt SD towards that of pure Ir. However, the Ir@Pt SD sample is still intrinsically different from the simple combination of both Ir and Pt surface, as the TOF for glycerol conversion (Figure 6) and $C_{3}$ hydrocarbon production (Figure 7) were 
not intermediate to pure Pt and pure Ir. As proposed by many studies [4, 38, 48], glycerol conversion is initiated by the chemisorption of glycerol on metal active sites, followed by the direct C-O bond cleavage or $\mathrm{C}-\mathrm{H}$ bond cleavage. Therefore, compared to the effect of reduced $\mathrm{H}_{2}$ adsorption on overlaying $\mathrm{Pt}$ active sites, the synergistic effect between Ir sites and Pt sites is considered to be less critical in the enhancement of glycerol hydrogenolysis over Ir@Pt SD. The essential difference between Ir@Pt SD and the simple combination of Ir and Pt surface is also demonstrated by the differences in adsorption and reactivity between the Ir@Pt SD and the Ir-Pt bimetallic sample.

Catalytic hydrodeoxygenation of 1-propanol and 2-propanol at $300^{\circ} \mathrm{C}$ under the same reaction condition was also tested to investigate the deoxygenation reactivity of primary and secondary alcohols. Pure Ir, pure Pt and Ir@Pt SD catalyst were tested. Gas phase selectivity and TOF of $\mathrm{C}_{3}$ hydrocarbon (propane and propylene) in 1-propanol hydrodeoxygenation as a function of WHSV is shown in Figure 9 and Figure 10, respectively. $\mathrm{C}_{3}$ hydrocarbons were target products (with C-O bond cleavage and no C-C bond cleavage). Other products detected include $\mathrm{CO}, \mathrm{CO}_{2}$, methane, ethane, ethylene, and ethanol. Ethanol is the only liquid phase product detected, with more than $50 \%$ of 1 -propanol feed being transformed into ethanol. The presence of ethanol confirmed the direct C-C bond scission in 1-propanol hydrogenolysis. This direct hydrogenolysis is also observed by de Vlieger et al. reporting that methanol is formed during ethanol reforming over $\mathrm{Pt}^{-} \mathrm{Al}_{2} \mathrm{O}_{3}$ as a result of $\mathrm{C}-\mathrm{C}$ bond cleavage [49]. This $\mathrm{C}-\mathrm{C}$ bond cleavage is likely to be catalyzed by both the solid acid support (silica-alumina) and metallic active sites, because $\mathrm{C}-\mathrm{C}$ bond cleavage products were detected in support-catalyzed reaction as mentioned above, and Wawrzetz et al. have shown that unsupported Pt black also generated ethylene glycol in aqueous phase glycerol reforming [38].

It can be seen in Figure 9 that for pure platinum, less than $40 \%$ of gas phase products were transformed into hydrocarbons, while more than $60 \%$ of gas phase products in the pure iridium- 
catalyzed reaction were $\mathrm{C}_{3}$ hydrocarbons. Ir@Pt SD displayed an intermediate value between pure iridium and pure platinum. In terms of TOF of $C_{3}$ hydrocarbon production (Figure 10), Ir@Pt SD showed a comparable value relative to pure platinum, while the pure iridium catalyst was significantly less active than the other two catalysts tested. The conversion of 1-propanol over Ir@Pt SD indicates the potential to take advantage of pure iridium without sacrificing the reactivity of the overlayer catalyst. This also demonstrated the viability by combining metals of high selectivity as the parent metal and metals of high reactivity as the overlayer to prepare overlayer catalyst with both high reactivity and selectivity.

The TOF of $\mathrm{C}_{3}$ hydrocarbon (propane and propylene) in the hydrodeoxygenation of 2-propanol as a function of WHSV is shown in Figure 11. Detected gas phase products included methane, ethane, propane, and propylene, while no liquid phase products were detected. Selectivity toward $\mathrm{C}_{3}$ hydrocarbons for all three catalysts was close to $100 \%$, which means the deoxygenation pathway was dominant in the conversion of 2-propanol for all catalysts. This is consistent with a previous study showing that no C-C bond cleavage was observed in 2-propanol hydrodeoxygenation over 3 wt.\% $\mathrm{Pt} / \mathrm{Al}_{2} \mathrm{O}_{3}$, while 1-propanol hydrodeoxygenation produced $\mathrm{C}_{2}$ and $\mathrm{C}_{1}$ compounds [38]. The large difference between the turnover frequencies of 2-propanol (Figure 11) and 1-propanol (Figure 10) or glycerol (Figure 7) implies that the deoxygenation of a primary alcohol is likely to be relatively more rate-determining than the deoxygenation of a secondary alcohol in the hydrogenolysis of glycerol. This is not expected, as bond dissociation energies of $\mathrm{C}-\mathrm{O}$ bond in 1-propanol $(93.7 \pm 0.7 \mathrm{kcal} / \mathrm{mol})$ and 2propanol $(95.1 \pm 1 \mathrm{kcal} / \mathrm{mol})$ are relatively similar [50]. Two theories have been proposed in the literature to explain the activity difference between 1-propanol and 2-propanol deoxygenation. It is suggested that the reaction intermediate of secondary alcohol dehydration is more stable than that of the primary alcohol, so that the elimination of a secondary alcohol is more kinetically controlled [48]. Another possible explanation is the inhibiting effect of adsorbed CO produced from 1-propanol deoxygenation. A kinetic model of propanol dehydration to propylene based on the Langmuir-Hinshelwood mechanism 
was developed by Cordero et al. [51] under reaction conditions similar to those in this work, and this model could also apply to the current study of 1-propanol and 2-propanol deoxygenation. The derived rate expression indicated that the formation rate of propylene is proportional to the amount of available active sites. As noted above, $\mathrm{CO}$ was produced in the 1-propanol deoxygenation but not detected in 2propanol deoxygenation. It is likely that in the reaction of 1-propanol deoxygenation, CO was produced and then adsorbed strongly on the catalyst surface, resulting in a loss of available active sites.

The existence of $C_{2}$ and $C_{1}$ compounds in 1-propanol hydrogenolysis suggested that the primary alcohol is more susceptible to decarbonylation ( $\mathrm{C}-\mathrm{C}$ bond cleavage), and thus the $\mathrm{C}-\mathrm{O}$ bond cleavage of primary alcohol is likely to be the inhibiting factor of efficiently producing fully deoxygenated hydrocarbon from glycerol for pure platinum and overlayer catalysts. Even though Ir@Pt SD showed lower $\mathrm{C}_{3}$ hydrocarbon production rate compared to pure $\mathrm{Pt}$ in 2-propanol conversion, taking into account that the deoxygenation of the secondary hydroxyl group is less rate-determining for the overall glycerol hydrogenolysis due to its fast reaction kinetics, it is reasonable that Ir@Pt SD still displayed the highest $C_{3}$ hydrocarbon production rate from glycerol hydrogenolysis.

A reaction scheme for aqueous phase glycerol hydrodeoxygenation adapted from previous literature studies $[5,38]$ is shown in Figure 12 . Generally, two types of processes are involved in the hydrodeoxygenation of glycerol: 1) dehydrogenation, hydrogenation, and decarbonylation mainly on metal active sites (in this study, Ir or Pt), and 2) deoxygenation/dehydration mainly on acidic supports (silica-alumina) $[6,38,52]$. C-C bond cleavage could be catalyzed through the dehydrogenation of glycerol on metal active sites to form glyceraldehyde, which is subsequently decarbonylated to form smaller alcohols [38]. In this study, low C-C bond cleavage selectivity was achieved by suppressing the formation of glyceraldehyde through overlayer structure. For C-O bond cleavage, glycerol was initially dehydrated on acid sites from silica-alumina support and subsequently hydrogenated to form 
propanediols on metal active sites [5]. For propanol hydrodeoxygenation, propanols were dehydrated on acidic sites to form carbocations, which was then converted to propylene or hydrogenated to propane [51]. Literature studies indicated that a balanced ratio of acid vs. metal sites is crucial in order to achieve high selectivity toward C-O bond cleavage: a sufficient amount of Brønsted acid sites for fast deoxygenation, and a sufficient amount of metallic sites to hydrogenate the unsaturated oxygenated compounds for further deoxygenation $[6,8]$. A linear correlation between glycerol conversion and the number of acid sites also suggests that glycerol dehydration is initiated on acid sites [53]. By improving the activity of the metal site, the desired acid/metal ratio may have been changed. The change in the ratio could be limiting the true activity (i.e., more acid sites may be necessary). Thus, additional studies further examining this site ratio may be warranted to see if the activity can be further optimized.

\section{4: Conclusions}

Ir@Pt overlayer catalysts supported on silica-alumina were synthesized using the directed deposition technique. Elemental analysis showed increased Pt loadings in Ir@Pt overlayer catalysts compared to previously synthesized Ni@Pt and Co@Pt overlayer catalysts, likely due to the close atomic radius of Ir relative to Pt so that the atomic size mismatch between the host metal and the parent metal is alleviated. $\mathrm{H}_{2}$ chemisorption and ethylene hydrogenation reactions have demonstrated that $\mathrm{H}_{2}$ heat of adsorption was reduced and hydrogen binding on the platinum surface was weakened by overlayer formation. Also, from $\mathrm{H}_{2}$ chemisorption and ethylene hydrogenation, Ir@Pt DD and Ir@Pt TD were speculated to form Pt multilayer structures, with weakened electronic and strain effects from the host metal (Ir) comparing to Ir@Pt SD.

Aqueous phase hydrodeoxygenation of glycerol showed that Ir@Pt SD is more active in glycerol

conversion compared to pure Pt. This enhanced reactivity validates the hypothesis that strong $\mathrm{H}_{2}$ adsorption on Pt would decrease catalytic reactivity, and weakened adsorption strength would improve 
the Pt reactivity. Ir@Pt SD displayed higher selectivity to $\mathrm{C}_{3}$ hydrocarbon production than pure Pt, as well as a lower TOF for undesired carbon oxides than pure Pt. Such high selectivity demonstrated the promising potential of overlayer catalysts in biomass-derived fuel production. The hydrodeoxygenation performance of overlayer catalysts also implies an efficient and effective way of utilizing precious platinum and selectively generates target products.

\section{Acknowledgements}

The authors would like to acknowledge funding support provided by National Science Foundation, Chemical, Bioengineering, Environmental and Transport Systems [CBET-0933017]. C. Zhang acknowledges support from the University of Wyoming through an Energy GA award. The authors gratefully thank Dr. Roy Geiss at Colorado State University for his help with TEM measurements. 


\section{References:}

[1] A.M. Ruppert, K. Weinberg, R. Palkovits, Angew. Chem. Int. Ed., 51 (2012) 2564-2601.

[2] M. Besson, P. Gallezot, C. Pinel, Chem. Rev., 114 (2014) 1827-1870.

[3] R.R. Davda, J.W. Shabaker, G.W. Huber, R.D. Cortright, J.A. Dumesic, Appl. Catal., B, 56 (2005) 171186.

[4] N.H. Tran, G.S.K. Kannangara, Chem. Soc. Rev., 42 (2013) 9454-9479.

[5] I. Gandarias, P.L. Arias, J. Requies, M.B. Guemez, J.L.G. Fierro, Appl. Catal., B, 97 (2010) 248-256.

[6] L. Vilcocq, A. Cabiac, C. Especel, S. Lacombe, D. Duprez, Catalysis Today, 189 (2012) 117-122.

[7] C. Zhao, W. Song, J.A. Lercher, ACS Catal., 2 (2012) 2714-2723.

[8] Y.T. Kim, J.A. Dumesic, G.W. Huber, J. Catal., 304 (2013) 72-85.

[9] P.M. Urban, A. Funke, J.T. Muller, M. Himmen, A. Docter, Appl. Catal., A, 221 (2001) 459-470.

[10] G.W. Huber, J.W. Shabaker, S.T. Evans, J.A. Dumesic, Appl. Catal., B, 62 (2006) 226-235.

[11] A. Gross, Top. Catal., 37 (2006) 29-39.

[12] J.G. Chen, C.A. Menning, M.B. Zellner, Surf. Sci. Rep., 63 (2008) 201-254.

[13] W.T. Yu, M.D. Porosoff, J.G.G. Chen, Chem. Rev., 112 (2012) 5780-5817.

[14] A. Ruban, B. Hammer, P. Stoltze, H.L. Skriver, J.K. Norskov, J. Mol. Catal. A: Chem., 115 (1997) 421-

429.

[15] E. Christoffersen, P. Liu, A. Ruban, H.L. Skriver, J.K. Norskov, J. Catal., 199 (2001) 123-131.

[16] A. Schlapka, M. Lischka, A. Gross, U. Kasberger, P. Jakob, Phys. Rev. Lett., 91 (2003) 016101.

[17] C. Zhang, Q. Lai, J.H. Holles, Catal. Sci. Technol., 6 (2016) 4632-4643.

[18] A.R. Morris, M.D. Skoglund, J.H. Holles, Appl. Catal., A, 489 (2015) 98-110.

[19] B.C. Miranda, R.J. Chimentao, J.B.O. Santos, F. Gispert-Guirado, J. Llorca, F. Medina, F.L. Bonillo, J.E. Sueiras, Appl. Catal., B, 147 (2014) 464-480.

[20] B. Cordero, V. Gomez, A.E. Platero-Prats, M. Reves, J. Echeverria, E. Cremades, F. Barragan, S. Alvarez, Dalton Trans., (2008) 2832-2838.

[21] C.H. Deng, X.Z. Duan, J.H. Zhou, X.G. Zhou, W.K. Yuan, S.L. Scott, Catal. Sci. Tech., 5 (2015) 15401547.

[22] Y. Nakagawa, Y. Shinmi, S. Koso, K. Tomishige, J. Catal., 272 (2010) 191-194.

[23] A. Iriondo, J.F. Cambra, V.L. Barrio, M.B. Guemez, P.L. Arias, M.C. Sanchez-Sanchez, R.M. Navarro, J.L.G. Fierro, Appl. Catal., B, 106 (2011) 83-93.

[24] E.S. Vasiliadou, A.A. Lemonidou, WIREs Energy and Environment, 4 (2015) 486-520.

[25] R. Weingarten, G.A. Tompsett, W.C. Conner, G.W. Huber, J. Catal., 279 (2011) 174-182.

[26] M.P. Latusek, B.P. Spigarelli, R.M. Heimerl, J.H. Holles, J. Catal., 263 (2009) 306-314.

[27] M.D. Skoglund, C.L. Jackson, K.J. McKim, H.J. Olson, S. Sabirzyanov, J.H. Holles, Appl. Catal. A: Gen., 467 (2013) 355-362.

[28] M.P. Latusek, R.M. Heimerl, B.P. Spigarelli, J.H. Holles, Appl. Catal., A, 358 (2009) 79-87.

[29] M. Womes, T. Cholley, F. Le Peltier, S. Morin, B. Didillon, N. Szydlowski-Schildknecht, Appl. Catal., A, 283 (2005) 9-22.

[30] H. Shi, O.Y. Gutierrez, A.M. Zheng, G.L. Haller, J.A. Lercher, J. Phys. Chem. C, 118 (2014) 20948-

20958.

[31] B. Sen, M.A. Vannice, J. Catal., 130 (1991) 9-20.

[32] J.M. Guil, A.P. Masia, A.R. Paniego, J.M.T. Menayo, Thermochim Acta, 312 (1998) 115-124.

[33] J. Greeley, M. Mavrikakis, Nat. Mater., 3 (2004) 810-815.

[34] M. Humbert, J. Chen, J. Catal., 257 (2008) 297-306.

[35] A. Roudgar, A. Gross, J. Electroanal. Chem., 548 (2003) 121-130.

[36] M. Lischka, C. Mosch, A. Gross, Electrochim. Acta, 52 (2007) 2219-2228.

[37] H. Shi, X.B. Li, G.L. Haller, O.Y. Gutierrez, J.A. Lercher, J. Catal., 295 (2012) 133-145. 
[38] A. Wawrzetz, B. Peng, A. Hrabar, A. Jentys, A.A. Lemonidou, J.A. Lercher, J. Catal., 269 (2010) 411420.

[39] S. Wang, K.H. Yin, Y.C. Zhang, H.C. Liu, ACS Catal., 3 (2013) 2112-2121.

[40] E.P. Maris, R.J. Davis, J. Catal., 249 (2007) 328-337.

[41] Z.W. Huang, F. Cui, H.X. Kang, J. Chen, C.G. Xia, Appl. Catal., A, 366 (2009) 288-298.

[42] K.L. Deutsch, D.G. Lahr, B.H. Shanks, Green Chem., 14 (2012) 1635-1642.

[43] J. Courtois, W.X. Du, E. Wong, X.W. Teng, N.A. Deskins, Appl. Catal., A, 483 (2014) 85-96.

[44] N. Li, G.W. Huber, J. Catal., 270 (2010) 48-59.

[45] Y. Amada, Y. Shinmi, S. Koso, T. Kubota, Y. Nakagawa, K. Tomishige, Appl. Catal., B, 105 (2011) 117-

127.

[46] M. Tamura, Y. Amada, S.B. Liu, Z.L. Yuan, Y. Nakagawa, K. Tomishige, J. Mol. Catal. A: Chem., 388 (2014) 177-187.

[47] Y. Nakagawa, X.H. Ning, Y. Amada, K. Tomishige, Appl. Catal., A, 433 (2012) 128-134.

[48] J. ten Dam, U. Hanefeld, Chemsuschem, 4 (2011) 1017-1034.

[49] D.J.M. de Vlieger, B.L. Mojet, L. Lefferts, K. Seshan, J. Catal., 292 (2012) 239-245.

[50] Y.-R. Luo, Handbook of bond dissociation energies in organic compounds, CRC press 2002.

[51] J. Bedia, R. Ruiz-Rosas, J. Rodríguez-Mirasol, T. Cordero, J. Catal., 271 (2010) 33-42.

[52] S.N. Delgado, D. Yap, L. Vivier, C. Especel, J. Mol. Catal. A: Chem., 367 (2013) 89-98.

[53] M. Balaraju, V. Rekha, P.S.S. Prasad, B.L.A.P. Devi, R.B.N. Prasad, N. Lingaiah, Appl. Catal., A, 354

(2009) 82-87. 
Table 1. Physical-chemical properties of samples prepared.

\begin{tabular}{lllllcc}
\hline Sample & $\begin{array}{l}\text { Result } \\
(\text { wt.\%) }\end{array}$ & Metal & $\begin{array}{l}\text { Dispersion } \\
(\%)\end{array}$ & $\begin{array}{l}\text { Calculated } \\
\text { \% overlayer }\end{array}$ & $\begin{array}{l}\text { Metal particle size from } \\
\mathrm{H}_{2} \text { chemisorption (nm) }\end{array}$ & $\begin{array}{l}\text { Crystallite size } \\
\text { from XRD (nm) }\end{array}$ \\
\hline 2 wt.\% Ir parent & - & $\mathrm{Ir}$ & 14.6 & & 7.6 & 8.0 \\
$\mathrm{Ir} @ \mathrm{Pt} \mathrm{SD}$ & 0.12 & $\mathrm{Pt}$ & 10.8 & $43 \%$ & 10.6 & 9.7 \\
$\mathrm{Ir} @ \mathrm{Pt} \mathrm{DD}$ & 0.24 & $\mathrm{Pt}$ & 11.2 & $109 \%$ & 10.2 & 9.5 \\
$\mathrm{Ir} @ \mathrm{Pt} \mathrm{TD}$ & 0.39 & $\mathrm{Pt}$ & 9.0 & $172 \%$ & 12.4 & 10.8 \\
$\mathrm{Ir}-\mathrm{Pt}$ & 0.20 & $\mathrm{Pt}$ & 21.9 & & 5.1 & 6.9 \\
& & & & & 3.4 & 5.1 \\
$\mathrm{Pt} / \mathrm{SiO}_{2}-\mathrm{Al}_{2} \mathrm{O}_{3}$ (reactivity) & 0.49 & $\mathrm{Pt}$ & 33.4 & & & \\
& & & & & 1.6 & 2.1 \\
$\mathrm{Pt} / \mathrm{SiO}_{2}-\mathrm{Al}_{2} \mathrm{O}_{3}$ (isotherms) & 5.2 & $\mathrm{Pt}$ & 73.9 & & & \\
\hline
\end{tabular}


Figure 1. X-ray diffraction patterns of silica-alumina supported catalysts. Platinum loadings determined from ICP-OES are also denoted.

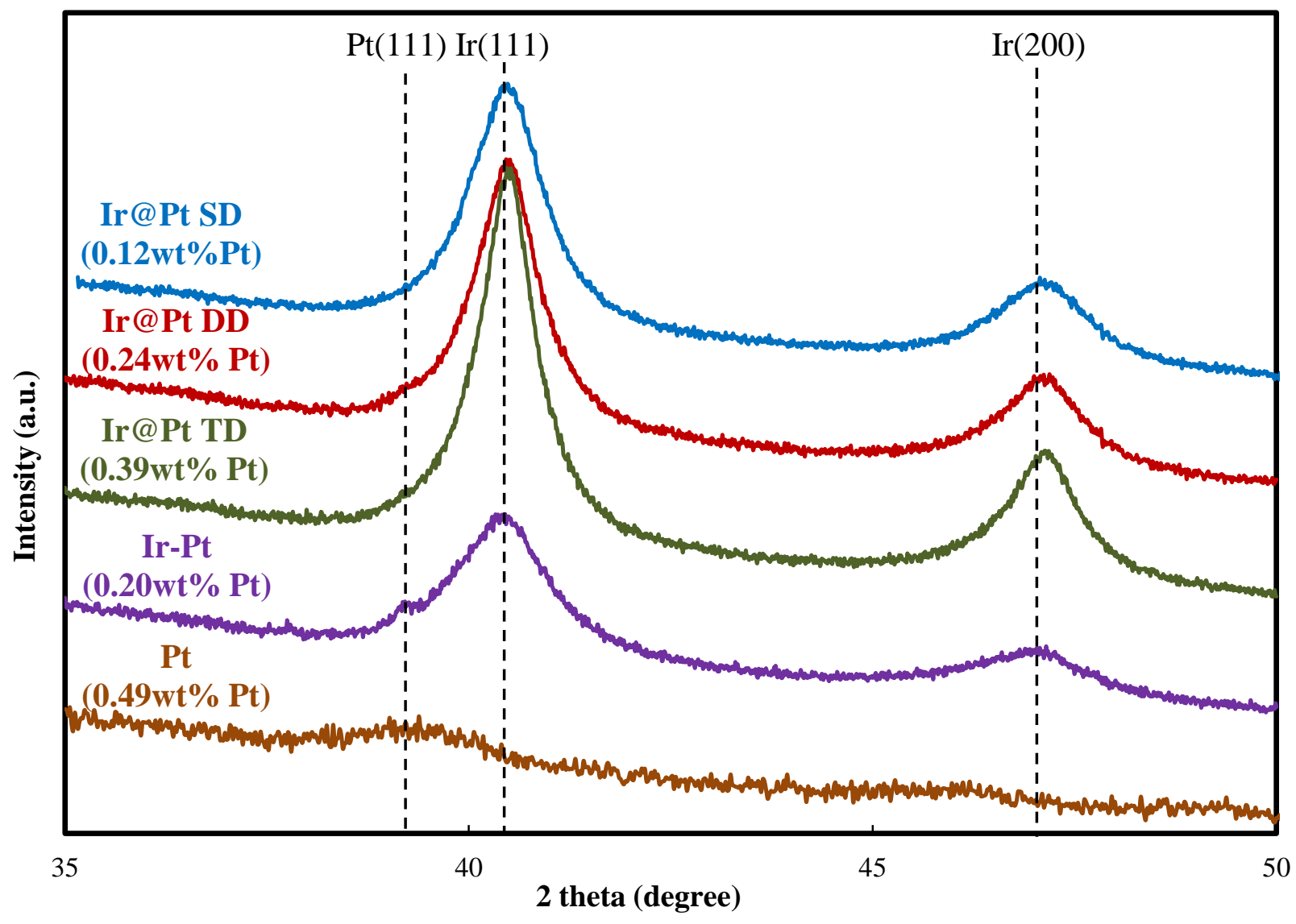


Figure 2. Transmission electron microscopy images of Ir@Pt SD: (a) TEM image, (b) TEM image, (c) HAADF-STEM image of overlayer metal particles, (d) EDX elemental mapping of Ir and Pt of (c), (e) HAADF-STEM of an overlayer metal particle, and (f) EDX line scan profiles of Ir and Pt recorded along the line showed in (e).
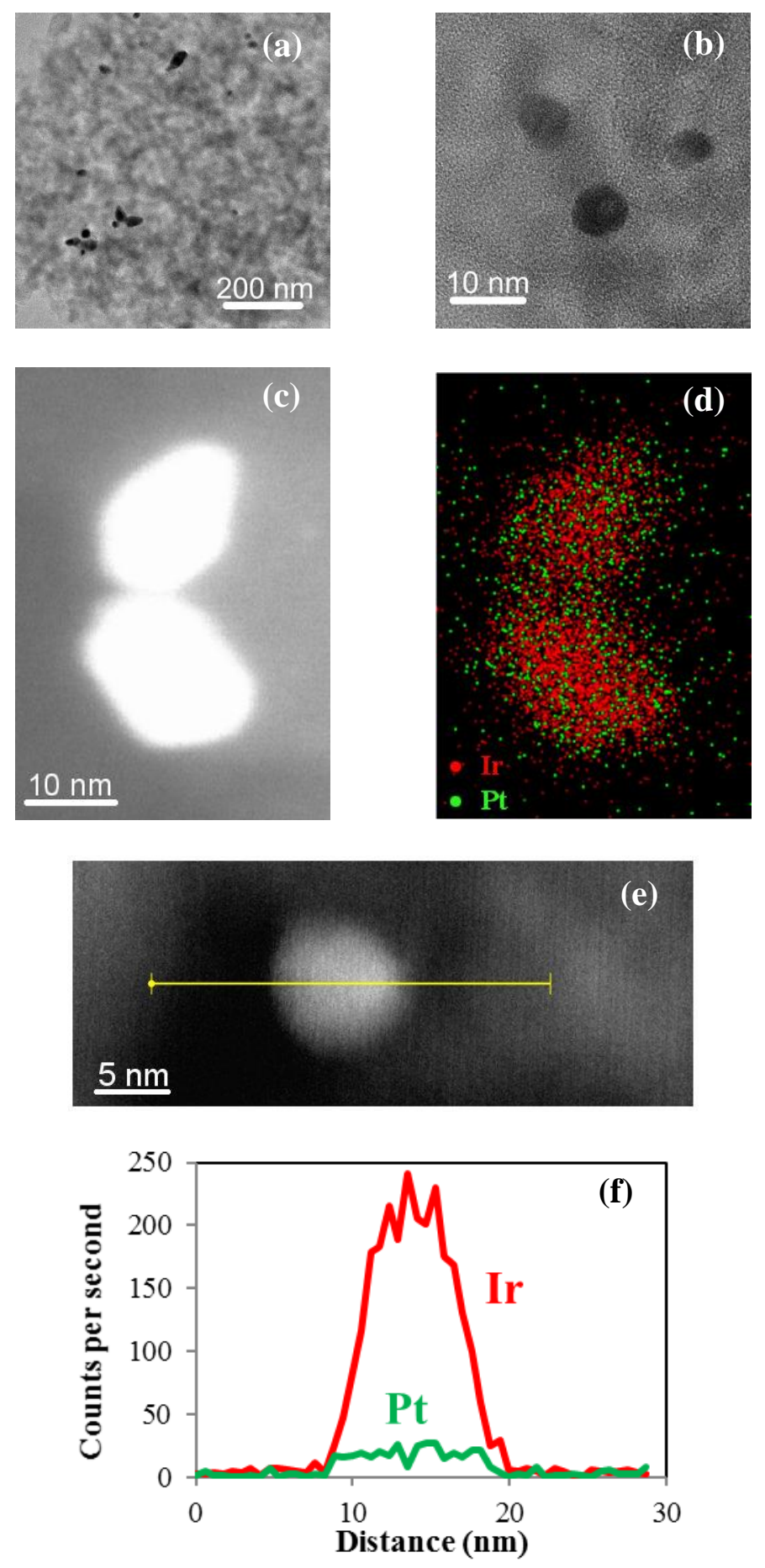
Table 2. Heat of $\mathrm{H}_{2}$ adsorption calculated from Clausius-Clapeyron equation.

\begin{tabular}{ll}
\hline Sample & Calculated $\mathrm{H}_{2}$ heat of adsorption $(\mathrm{kJ} / \mathrm{mol})$ \\
\hline 2 wt.\% Ir parent & 36 \\
$\mathrm{Ir} @ \mathrm{Pt} \mathrm{SD}$ & 28 \\
$\mathrm{Ir} @ \mathrm{Pt}$ DD & 46 \\
$\mathrm{Ir} @ \mathrm{Pt}$ TD & 41 \\
$\mathrm{Ir}-\mathrm{Pt}$ & 46 \\
& \\
$\mathrm{Pt}$ & 59 \\
\hline
\end{tabular}


Figure 3. Correlation between heat of hydrogen adsorption of platinum overlayer catalysts and calculated d-band center energy from reference [14].

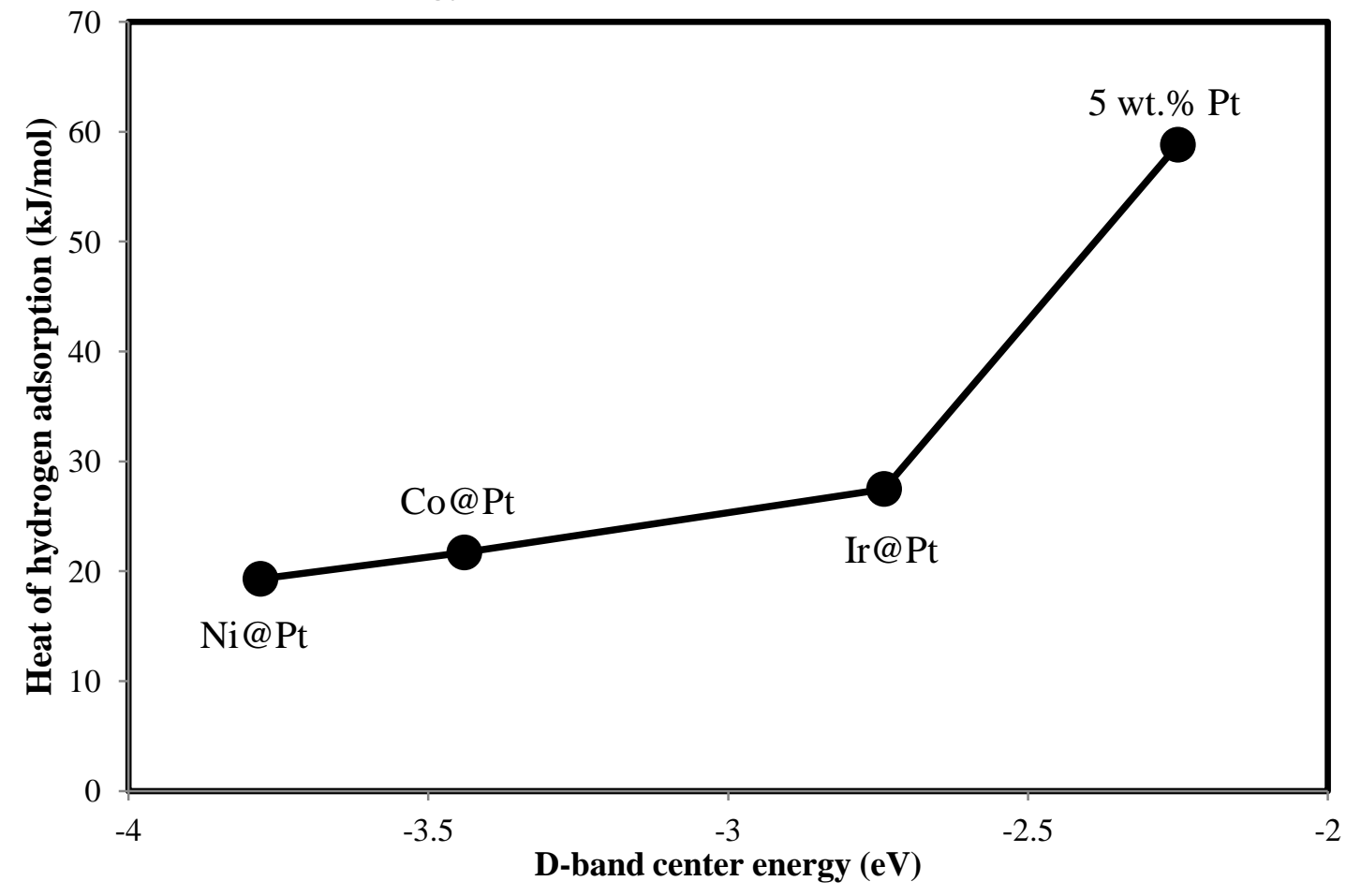


Figure 4. Arrhenius-type plot of silica-alumina supported catalysts for ethylene hydrogenation.

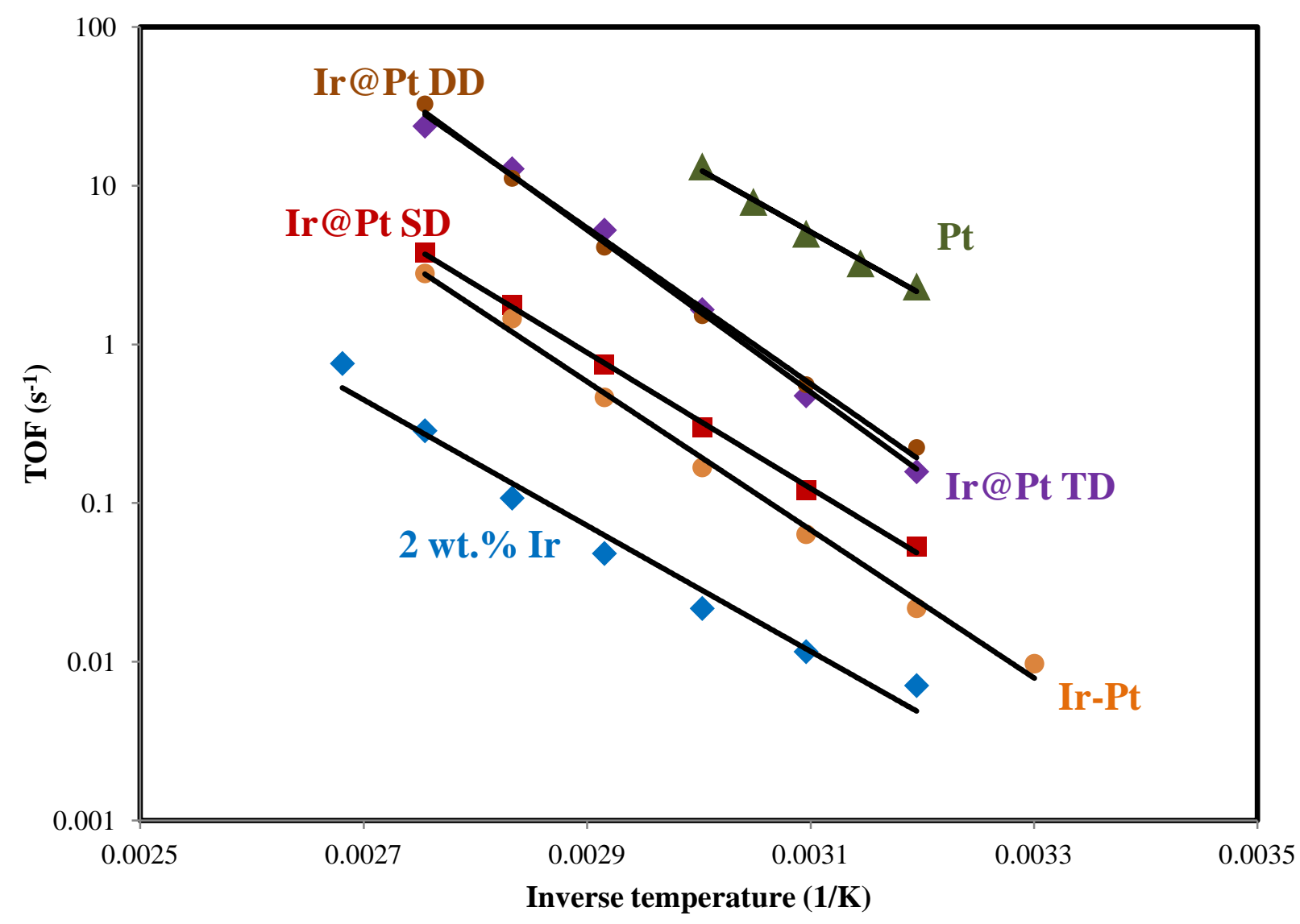


Table 3. Calculated apparent activation energy for ethylene hydrogenation and reaction orders with respect to hydrogen and ethylene.

\begin{tabular}{lcll}
\hline \multirow{2}{*}{ Catalyst } & $\begin{array}{c}\text { Apparent activation } \\
\text { energy }(\mathrm{kJ} / \mathrm{mol})\end{array}$ & $\mathrm{H}$ Reaction orders & \\
\cline { 3 - 4 } & 76 & 1.00 & $\mathrm{C}_{2} \mathrm{H}_{4}$ \\
\hline 2 wt.\% Ir parent & 82 & 0.67 & 0.96 \\
Ir@Pt SD & 102 & 0.71 & 0.61 \\
Ir@Pt DD & 94 & 0.65 & 0.54 \\
Ir@Pt TD & 89 & 0.84 & 0.54 \\
Ir-Pt & & & 0.34 \\
& 76 & 1.01 & 0.47 \\
$\mathrm{Pt}$ & & & \\
\hline
\end{tabular}


Figure 5. TOF of hydrocarbon production for overlayer catalysts in $10 \mathrm{wt} . \%$ glycerol APH reaction at $300^{\circ} \mathrm{C}$.

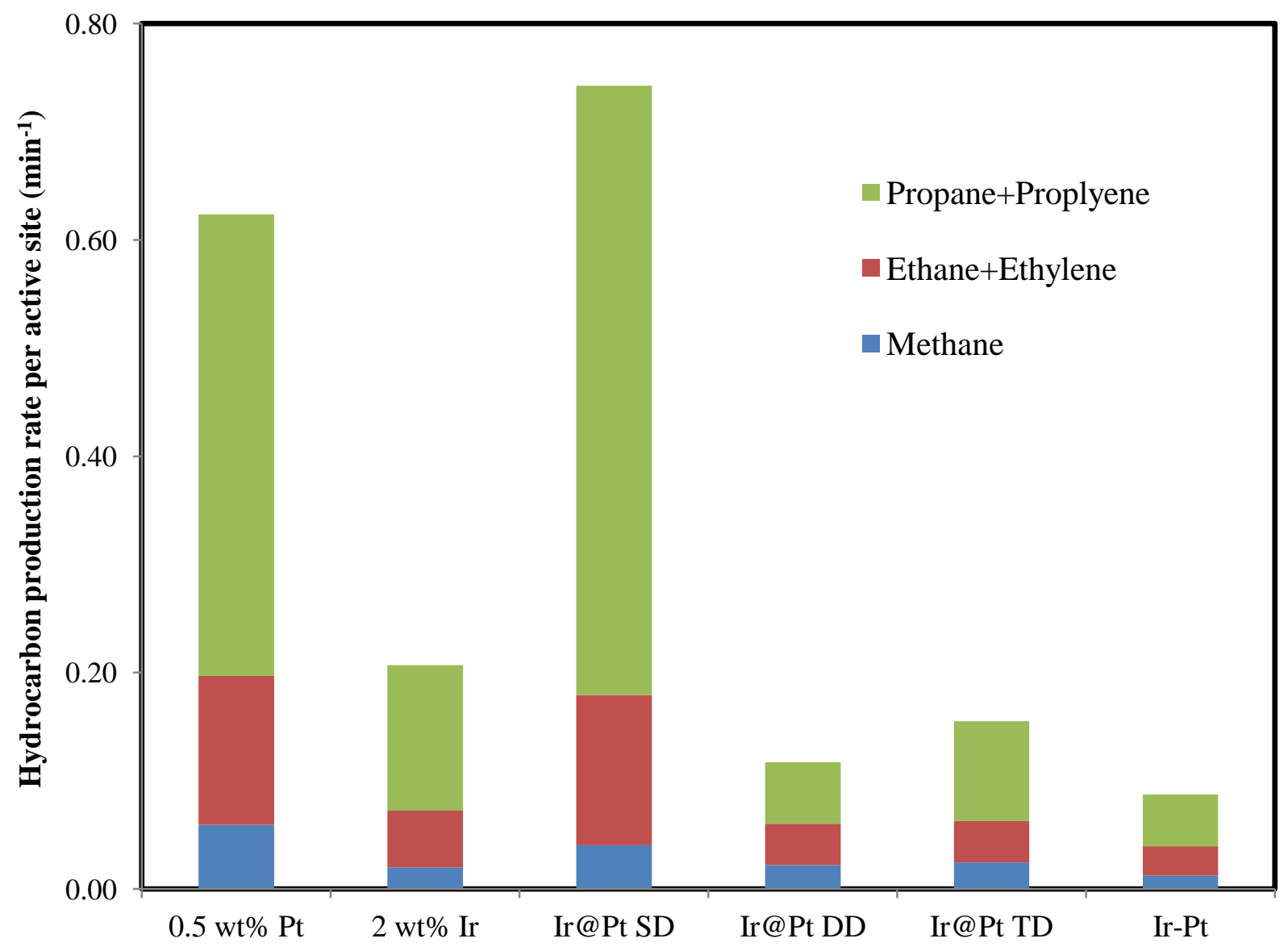


Table 4. Glycerol conversion and product selectivity values for all catalysts tested at $300^{\circ} \mathrm{C}$ at a weight hour space velocity of $4 \mathrm{~h}^{-1}$.

\begin{tabular}{|c|c|c|c|c|c|c|c|c|c|c|c|c|}
\hline \multirow{2}{*}{ Catalyst } & \multirow{2}{*}{$\begin{array}{l}\text { Conversion } \\
(\%)\end{array}$} & \multicolumn{10}{|c|}{ Carbon selectivity (\%) } & \multirow{2}{*}{$\begin{array}{l}\text { Carbon } \\
\text { balance }(\%)\end{array}$} \\
\hline & & 1,2-PrD & 1,3-PrD & 1-PrOH & 2-PrOH & $\mathrm{EtOH}$ & $\mathrm{MeOH}$ & EG & $\mathrm{HC}$ & $\mathrm{CO}_{\mathrm{x}}$ & Others & \\
\hline $\mathrm{Ir}$ & 71.6 & 14.2 & 37.7 & 7.3 & 2.5 & 25.0 & 2.2 & 7.9 & 0.2 & 0.9 & 2.1 & 78.0 \\
\hline Ir@Pt SD & 83.3 & 21.6 & 30.4 & 6.2 & 1.9 & 13.0 & 15.4 & 7.0 & 0.3 & 1.9 & 2.2 & 77.8 \\
\hline Ir@Pt DD & 89.2 & 13.1 & 36.1 & 10.5 & 5.8 & 10.8 & 10.2 & 5.8 & 0.1 & 2.0 & 5.5 & 80.3 \\
\hline Ir@Pt TD & 84.8 & 42.1 & 31.5 & 3.0 & 0.5 & 5.3 & 4.7 & 8.9 & 0.1 & 1.9 & 2.1 & 106.5 \\
\hline Ir-Pt & 91.4 & 24.2 & 24.6 & 3.5 & 2.1 & 13.7 & 14.3 & 14.3 & 0.1 & 2.2 & 0.7 & 114.5 \\
\hline $\mathrm{Pt}$ & 85.6 & 4.2 & 24.0 & 16.7 & 7.8 & 12.8 & 8.5 & 5.9 & 0.3 & 2.8 & $17.0 *$ & 84.4 \\
\hline
\end{tabular}

Reaction condition: $10 \mathrm{wt} . \%$ glycerol solution, hydrogen pressure 25.6 bar, catalyst $150 \mathrm{mg}$.

Products: 1,2-PrD, 1,2-propanediol; 1,3-PrD, 1,3-propanediol; 1-PrOH, 1-propanol; 2-PrOH, 2-propanol; $\mathrm{EtOH}$, ethanol; $\mathrm{MeOH}$, methanol; EG, ethylene glycol; $\mathrm{HC}$, hydrocarbon; $\mathrm{CO}_{\mathrm{x}}, \mathrm{CO}$ and $\mathrm{CO}_{2}$ combined. Others: glyceraldehyde, lactic acid, acetic acid, formic acid and propionic acid.

* Formic acid was detected in the liquid phase with a selectivity of $9.9 \%$ for pure $\mathrm{Pt}$, while this product was not detected for all other catalysts. 
Figure 6. TOF of glycerol conversion in glycerol hydrodeoxygenation as a function of weight hour space velocity (WHSV).

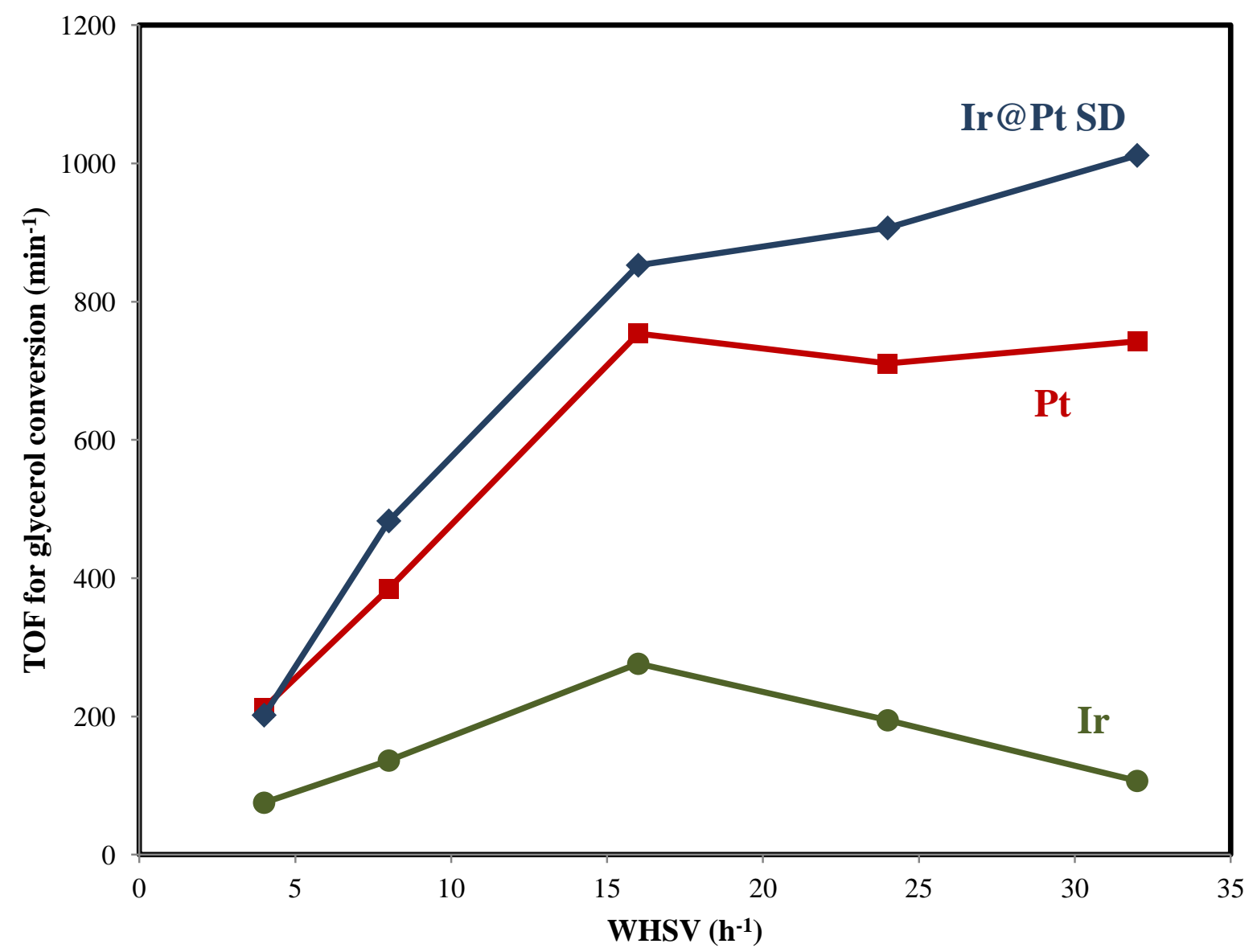


Figure 7. TOF of $\mathrm{C}_{3}$ hydrocarbon (propane and propylene) production in glycerol hydrodeoxygenation as a function of weight hour space velocity (WHSV) at $300^{\circ} \mathrm{C}$.

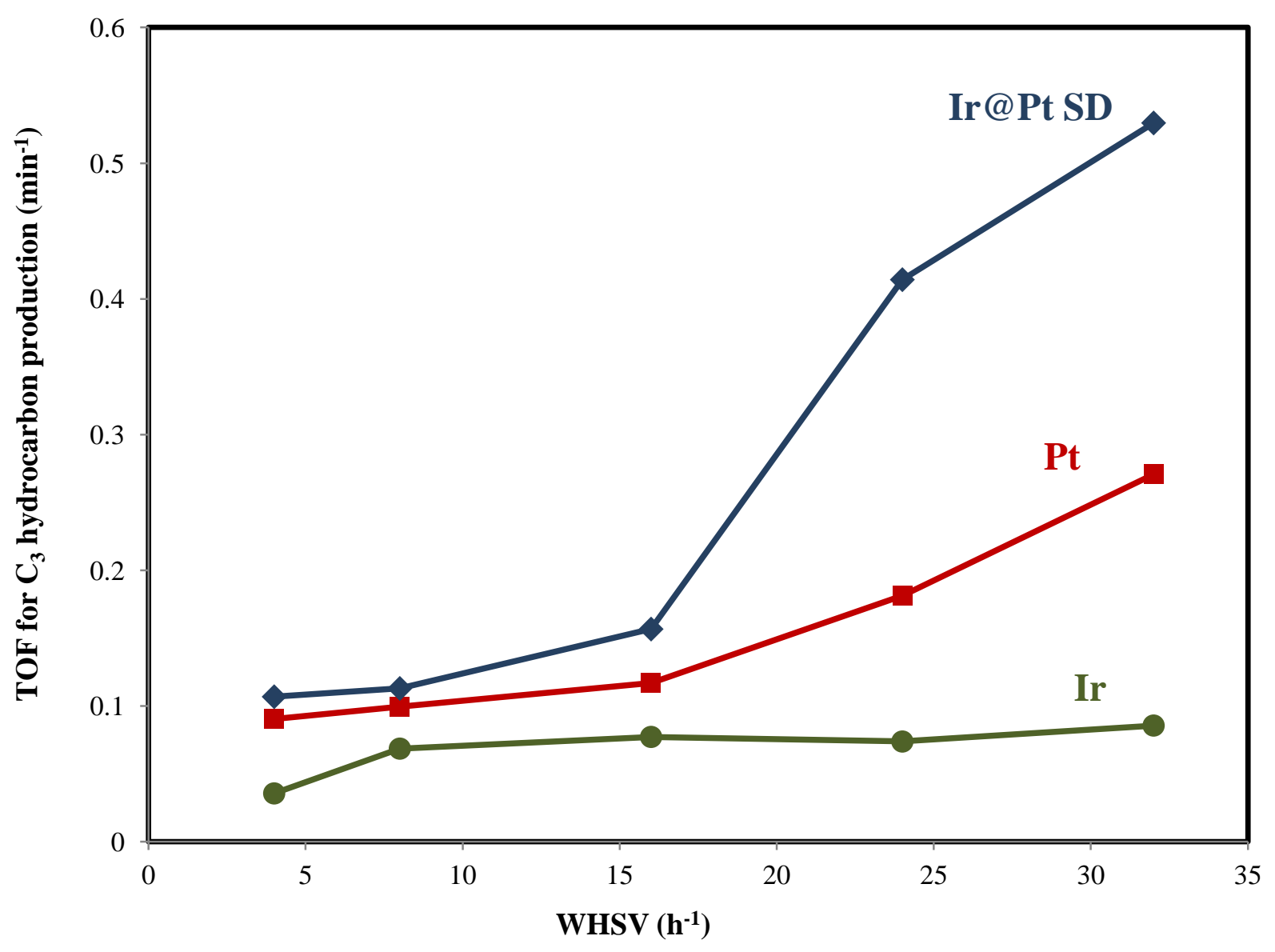


Figure 8. The selectivity ratios of carbon oxides to $C_{3}$ hydrocarbons as a function of weight hour space velocity (WHSV) in glycerol hydrodeoxygenation at $300^{\circ} \mathrm{C}$.

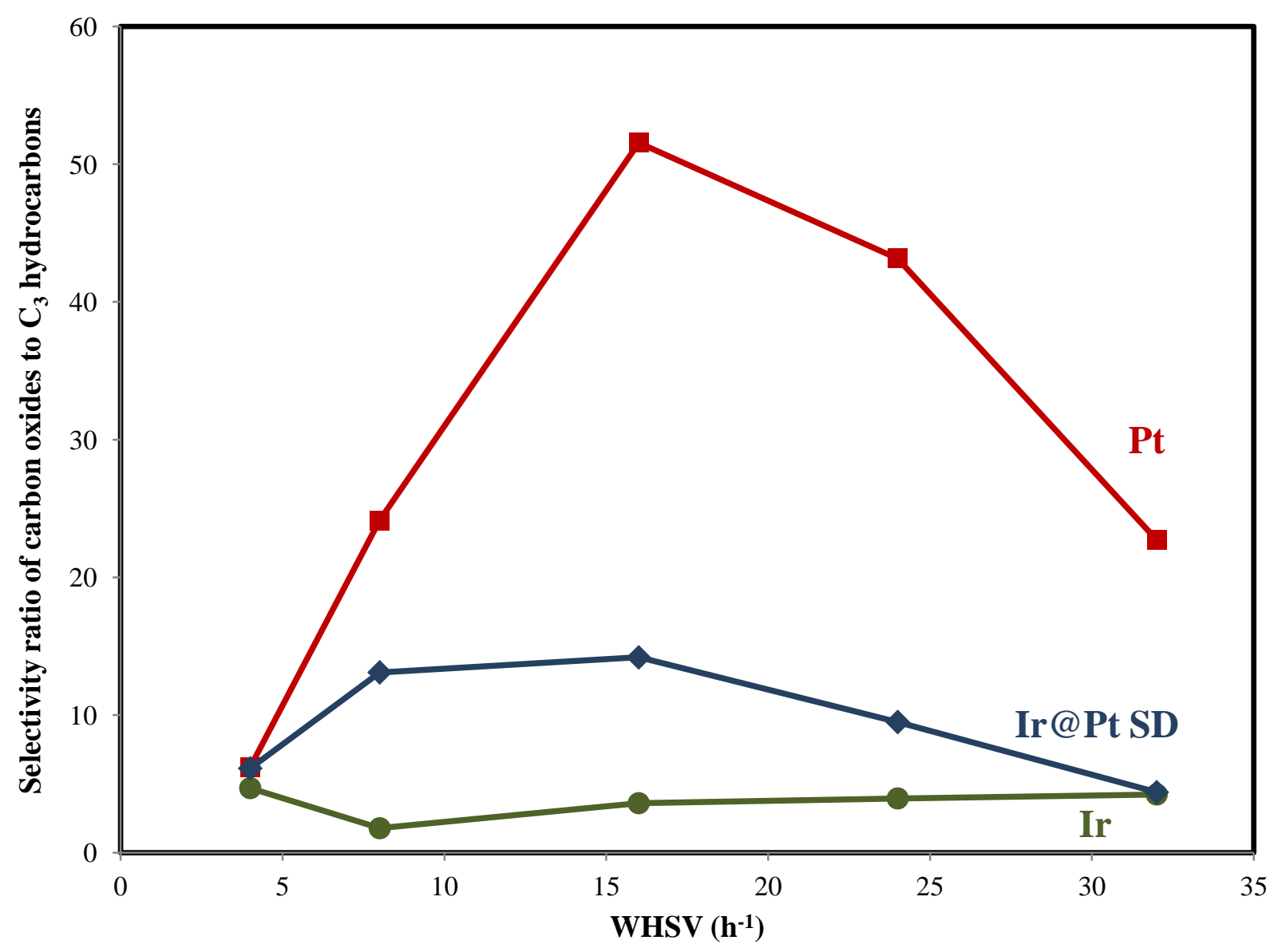


Figure 9. Gas phase selectivity toward propane and propylene as a function of WHSV in the hydrodeoxygenation of 1-propanol.

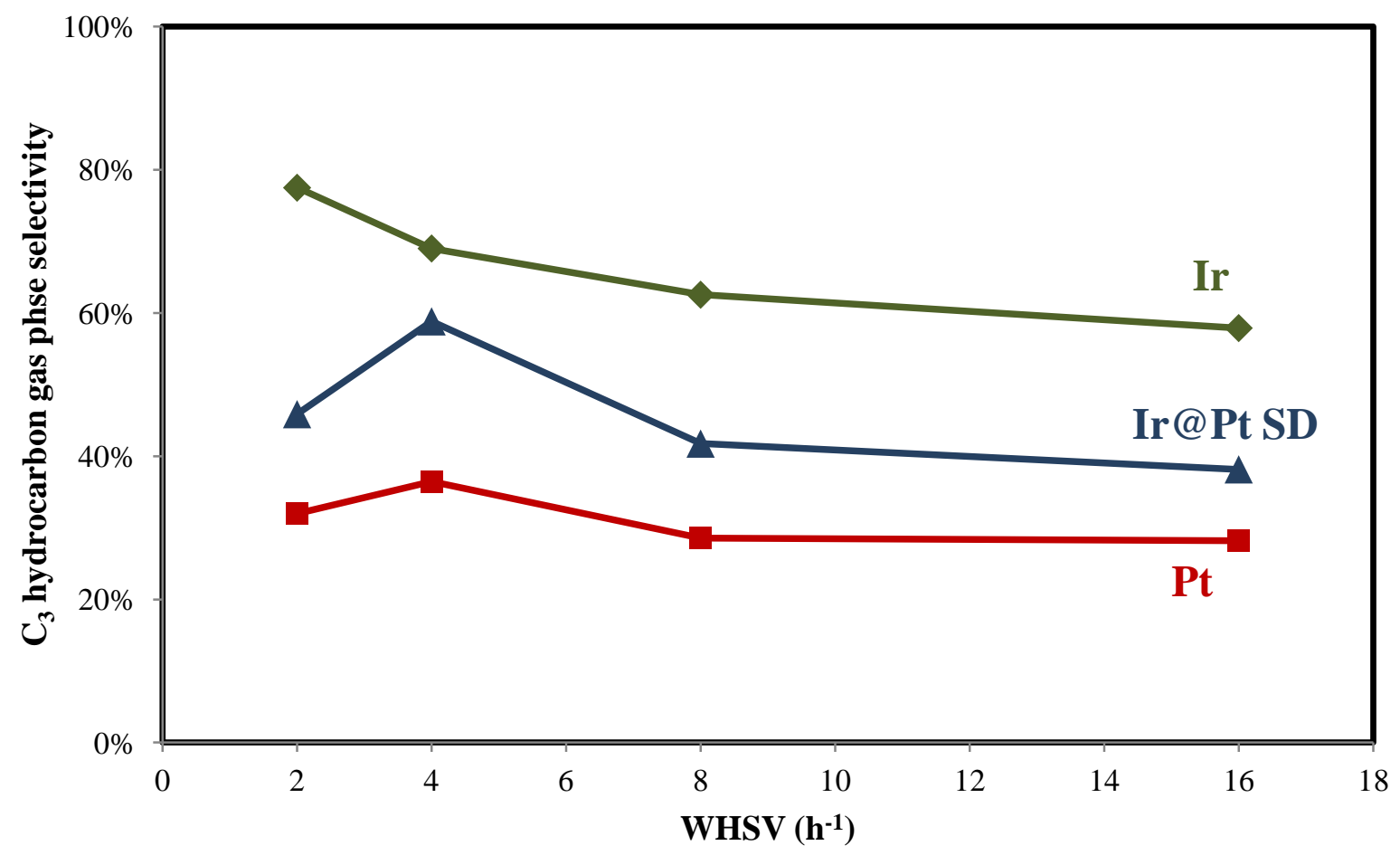


Figure 10. TOF of $\mathrm{C}_{3}$ hydrocarbon (propane and propylene) as a function of WHSV in the hydrodeoxygenation of 1-propanol.

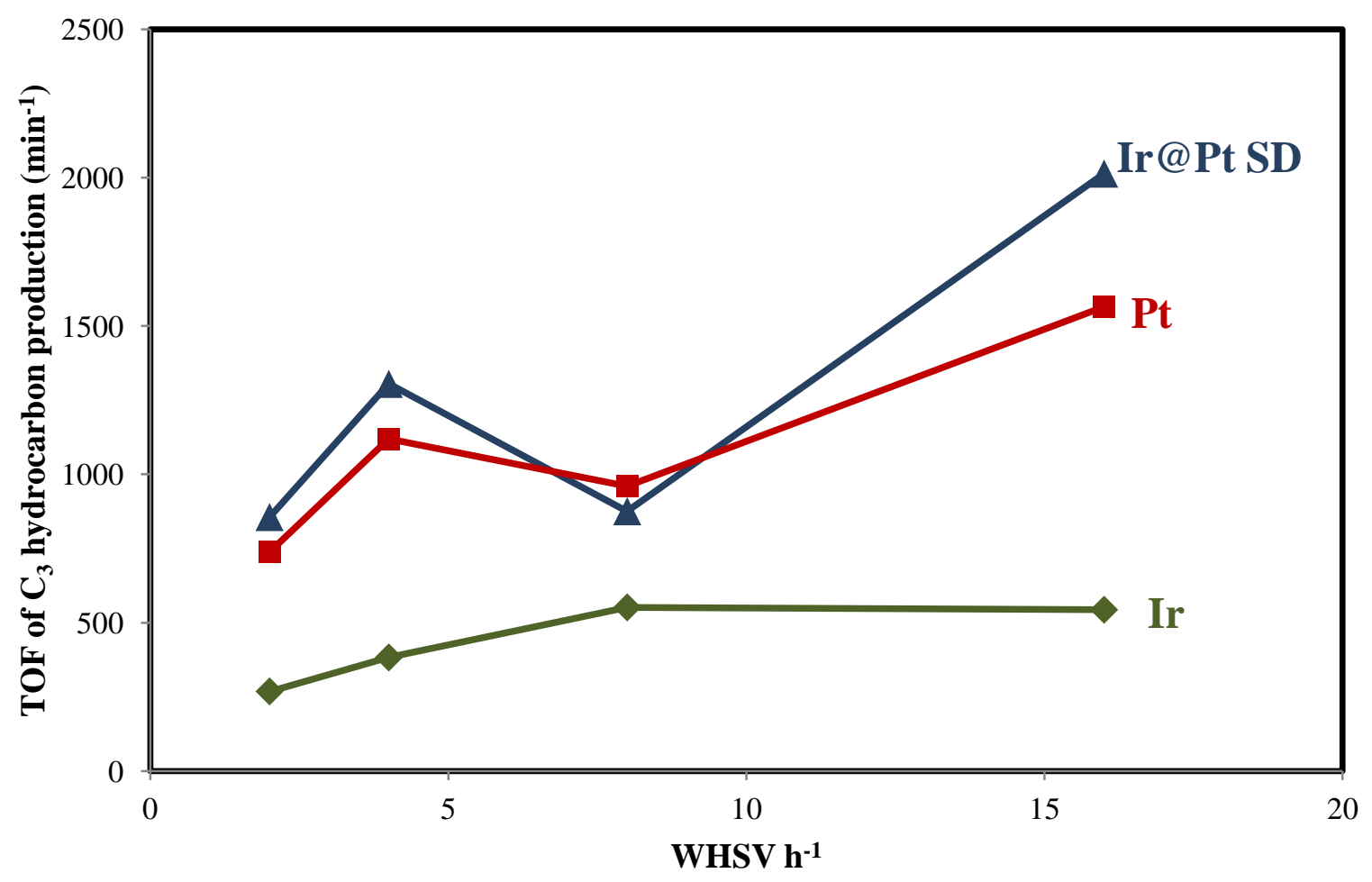


Figure 11. TOF of $\mathrm{C}_{3}$ hydrocarbon (propane and propylene) as a function of WHSV in the hydrodeoxygenation of 2-propanol.

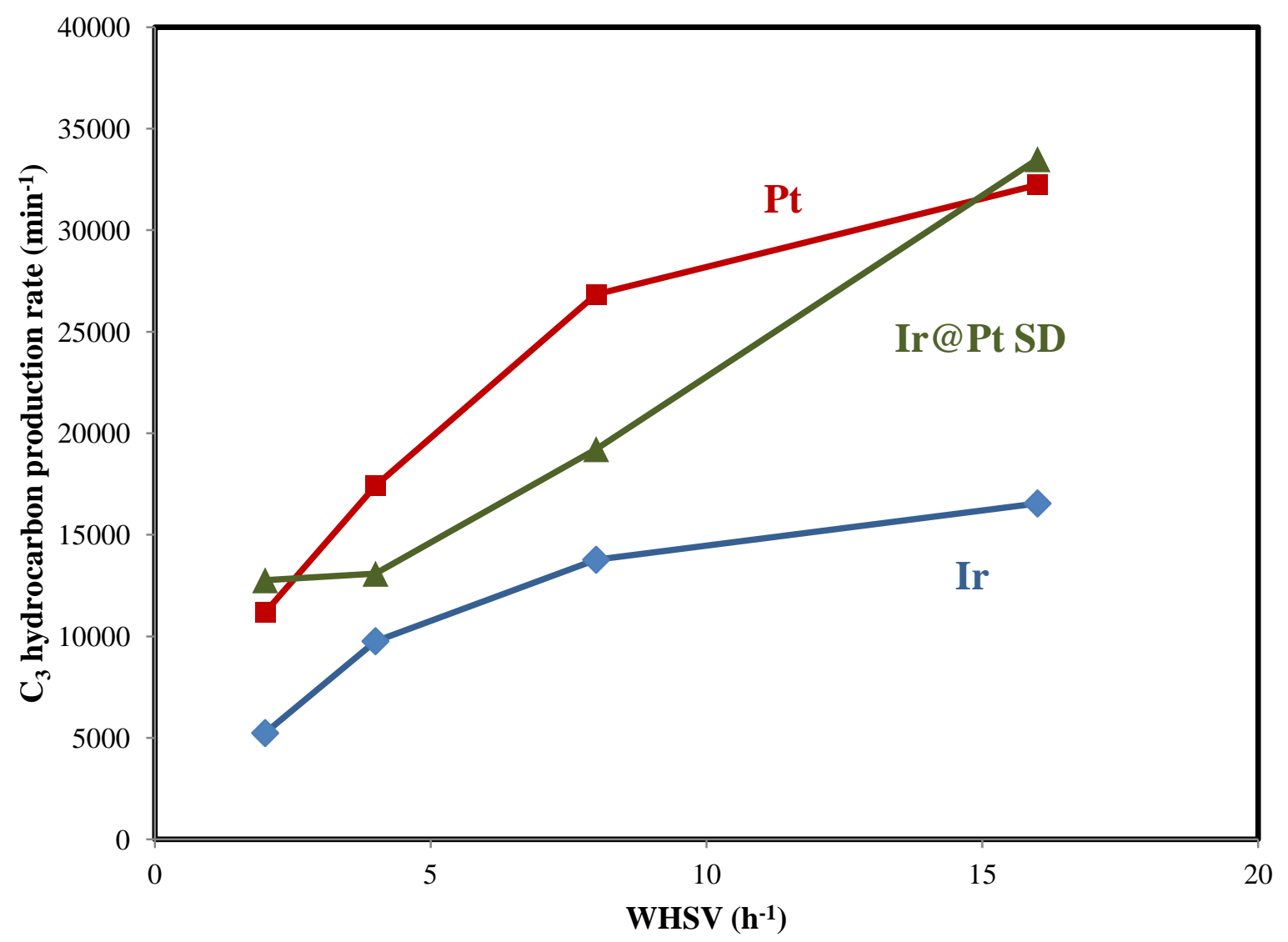


Figure 12. Proposed reaction scheme for aqueous phase glycerol hydrodeoxygenation.

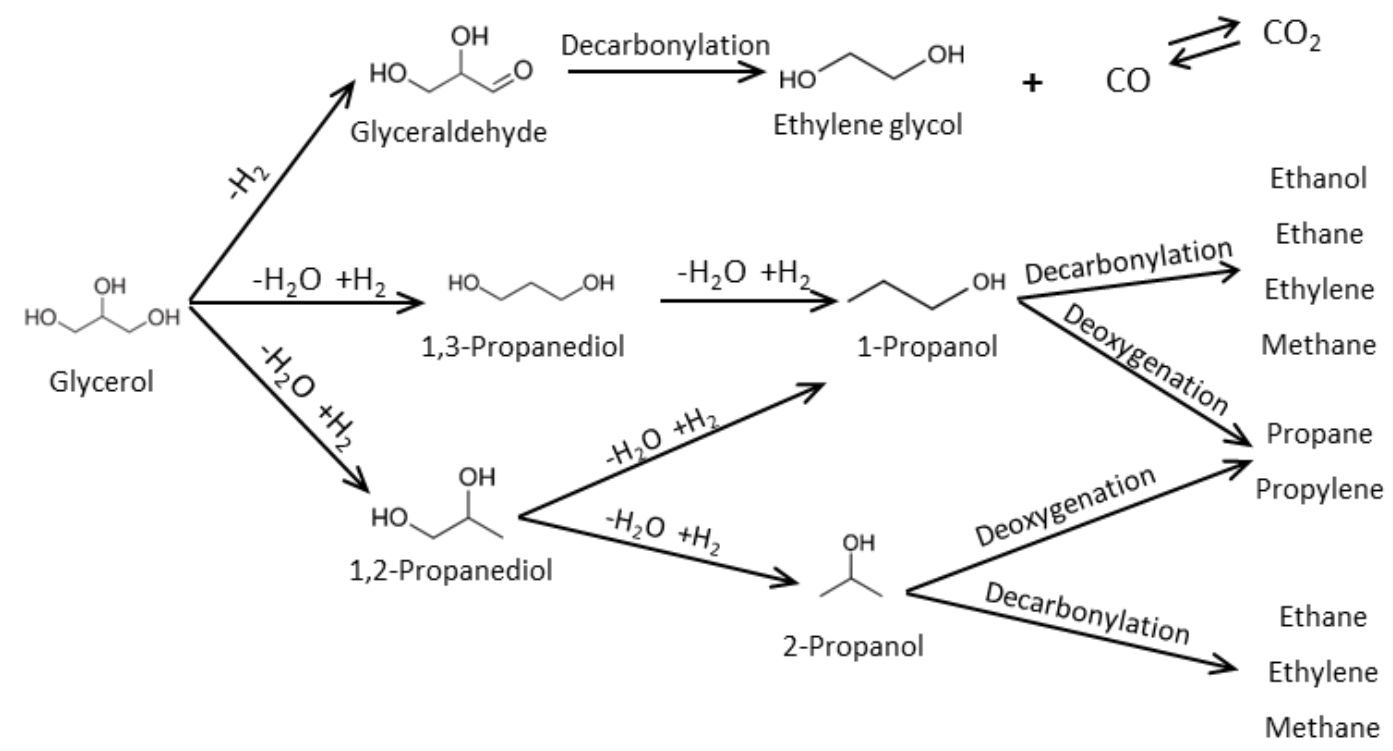




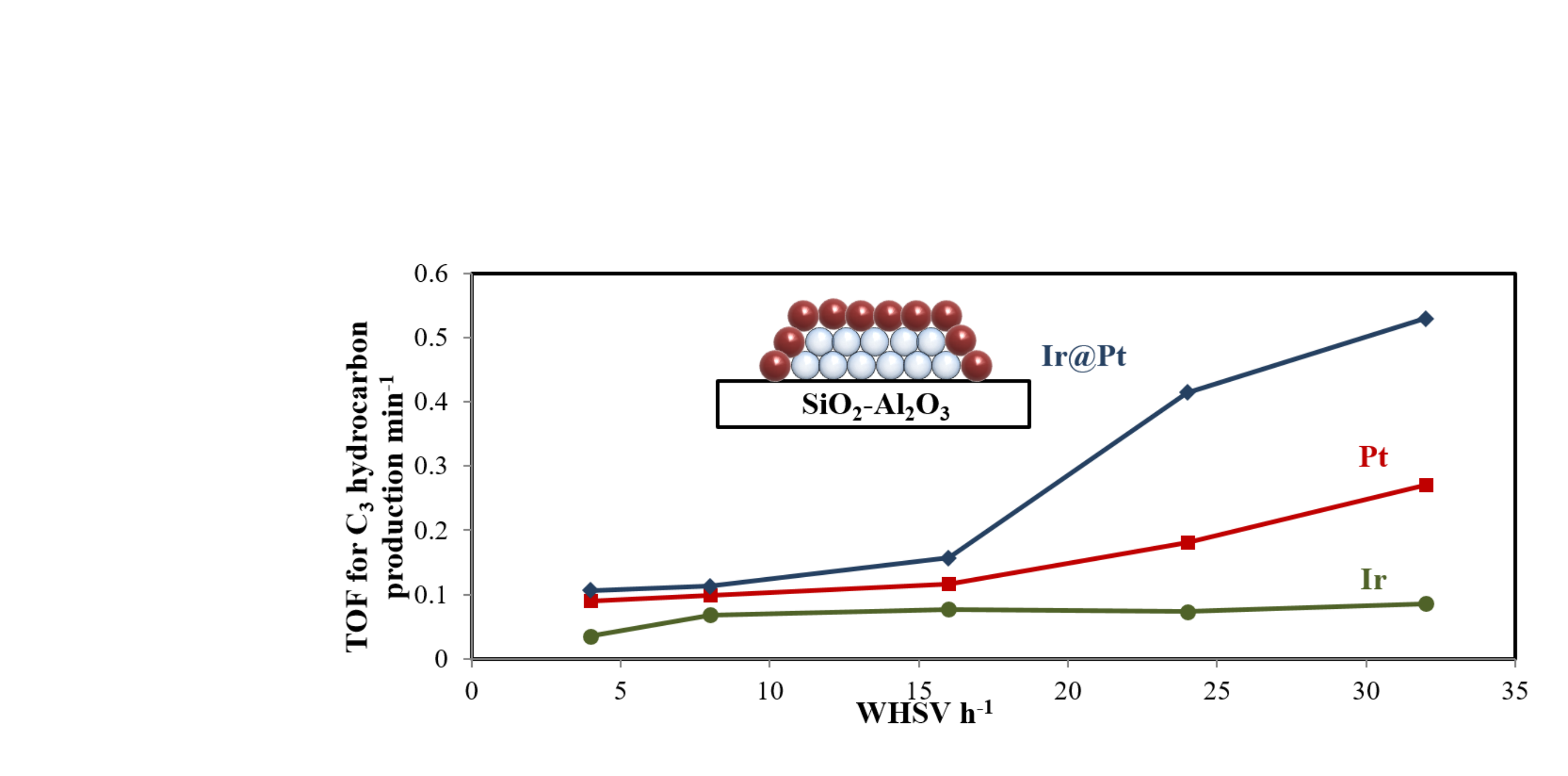

.

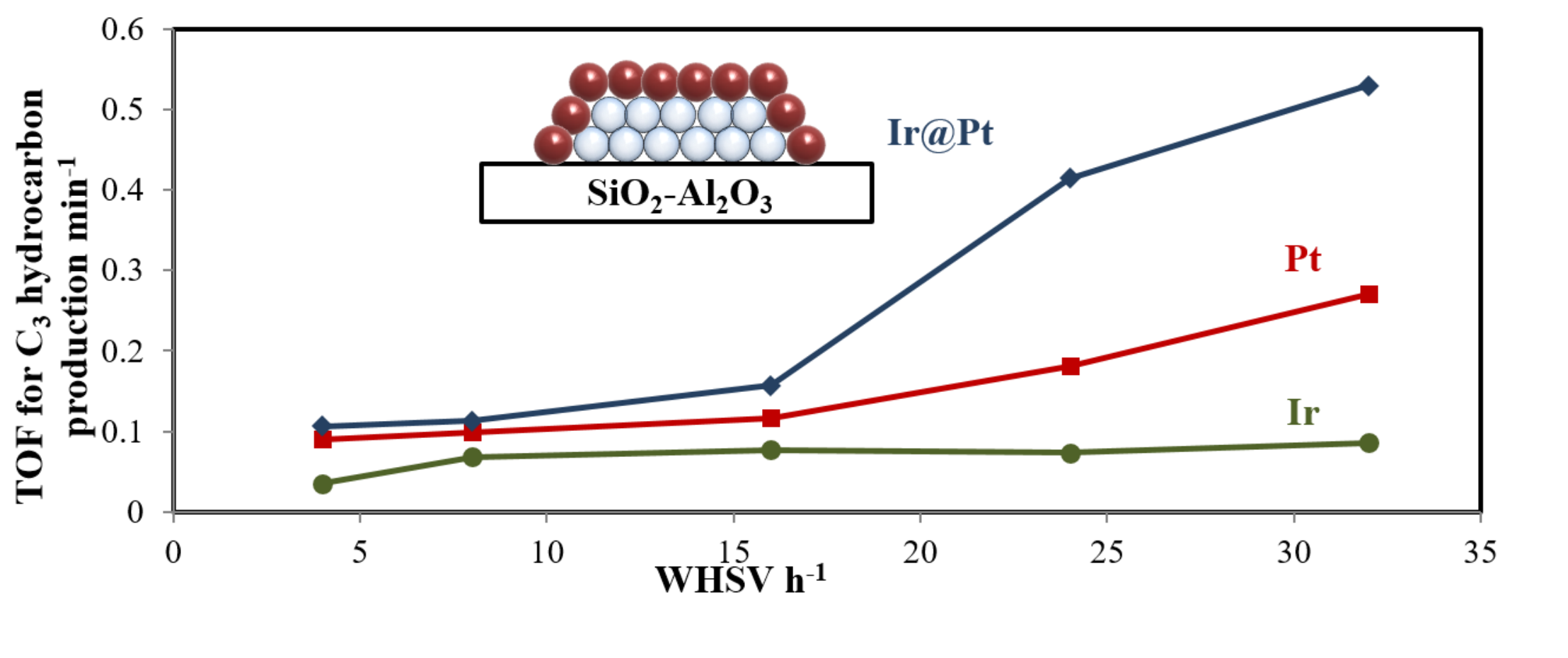

.

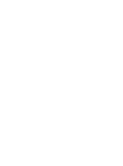
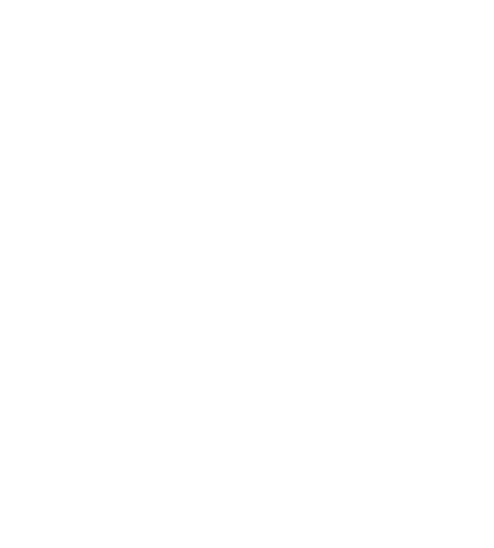

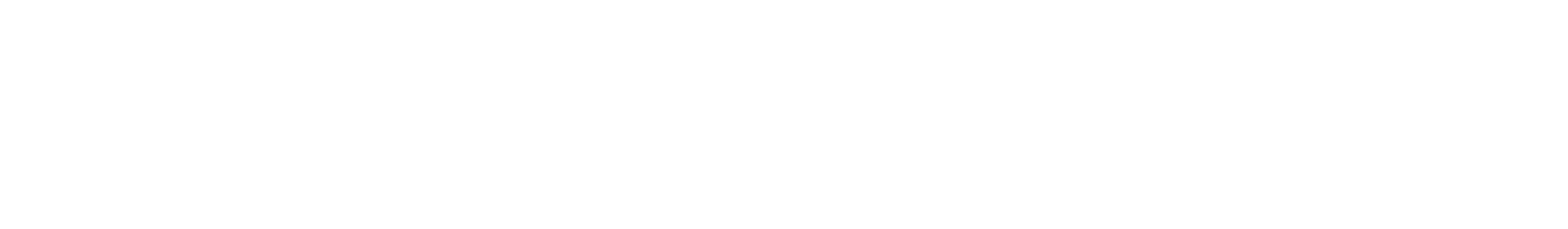
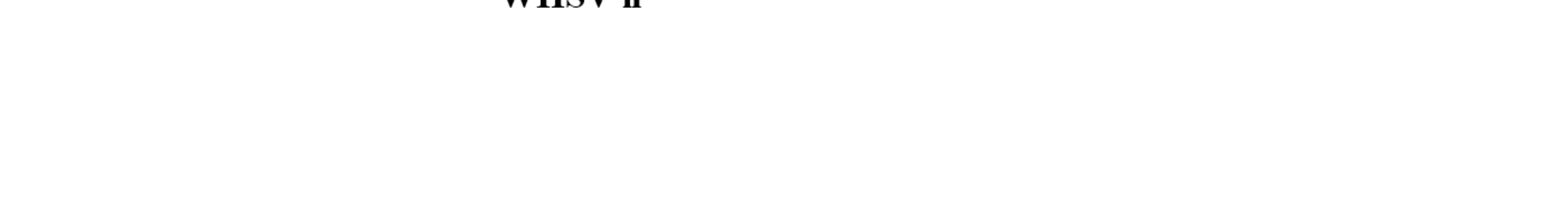